\title{
Time: The Biggest Pattern in Natural History Research
}

\author{
Nathalie Gontier ${ }^{1}{ }^{\mathbb{D}}$
}

Received: 11 October 2016/ Accepted: 13 October 2016/Published online: 28 October 2016

(C) Springer Science+Business Media New York 2016

\begin{abstract}
We distinguish between four cosmological transitions in the history of Western intellectual thought, and focus on how these cosmologies differentially define matter, space and time. We demonstrate that how time is conceptualized significantly impacts a cosmology's notion on causality, and hone in on how time is conceptualized differentially in modern physics and evolutionary biology. The former conflates time with space into a single spacetime continuum and focuses instead on the movement of matter, while the evolutionary sciences have a tradition to understand time as a given when they cartography how organisms change across generations over or in time, thereby proving the phenomenon of evolution. The gap becomes more fundamental when we take into account that phenomena studied by chrono-biologists demonstrate that numerous organisms, including humans, have evolved a "sense" of time. And micro-evolutionary/genetic, mesoevolutionary/developmental and macro-evolutionary phenomena including speciation and extinction not only occur by different evolutionary modes and at different rates, they are also timely phenomena that follow different periodicities. This article focusses on delineating the problem by finding its historical roots. We conclude that though time might be an obsolete concept for the physical sciences, it is crucial for the evolutionary sciences where evolution is defined as the change that biological individuals undergo in/over or through time.
\end{abstract}

Nathalie Gontier

nlgontier@fc.ul.pt

1 Applied Evolutionary Epistemology Lab, Centre for Philosophy of Science, University of Lisbon, Lisbon, Portugal
Keywords Cosmology $\cdot$ Cosmogony $\cdot$ Matter $\cdot$ Space $\cdot$ Time · Time's cycle · Time's arrow · Periodicity · Evolutionary epistemology

\section{Introduction}

Humans distinguish themselves from other biological organisms by developing intellectual knowledge on the world. The intellectual thoughts that we developed underlie cosmology-formation and in so far as they have been materialized in writings, we can reconstruct the genealogical trajectories of our intellectual schools of thought. From historical research, we know that western intellectual thought transitioned from naturalistic (sometimes called animistic) to theistic to scientific cosmologies, and congruent notions on causality have been called holistic, reductionist and statistical or interactional. Such analyses mostly focus on how cosmologies differentially define matter and space. Here we analyze instead how the various cosmologies define time and how this impacts their ideas on causality.

The ancient Greeks endorsed a circular time notion that was linearized by Judeo-Christian traditions that understood time as a sequence of historical events that have a unique cosmogonic beginning and a clear and known eschatological ending. This linear view of time became "scientified" by the natural history scholars who, inspired by the invention of the pendulum and the automated, mechanical clock, understood time first as a natural law-like phenomenon and later as absolute.

Today, the evolutionary sciences understand time both as an axis whereon or whereby they map phylogenetic speciation events in a Cartesian two- or three-dimensional coordinate system, and they understand (knowledge of) 
periodicity either as a trait or a characteristic present in the (life) cycle of many biological individuals (including organisms but also species). Modern physics on the contrary has come to question the existence of time by treating time and space as a single continuum and reducing time to the study of motion. Different notions of time therefore underlie a fundamental gap between current physical and evolutionary sciences. The primary aim here is to develop a better understanding of the problems associated with the (in)existence of time. This already results in a lengthy contribution and we therefore end the article with briefly outlining three suggestions on how time can remain a valid concept for the evolutionary sciences.

\section{The Four Western Cosmologies}

Cosmologies or worldviews provide epistemological frameworks for understanding the ontology or metaphysics of the universe which translates into philosophizing on the nature of existence by providing theories on matter, space and time. Transitions in intellectual history underlie changes in cosmologies and we distinguish between four such major transitions in western schools of thought. The classic Greek cosmology transitioned into the JudeoChristian cosmology that was overthrown by the rise of classical physics and natural history schools. We will argue that the latter are currently transitioning into a new and rising cosmology brought forth both by modern physics and modern evolutionary biology (Table 1).

One way we examine these transitions is by analyzing the cosmographies that depict the intellectual patterns that structure cosmologies. The ancient Greeks patterned the cosmos into wheels of time, chains of being and cycles of "coming and becoming" that transitioned into JudeoChristian scala naturae or stairways to heaven as well as historical chronologies on creation, that in turn transitioned into scientific tree and network diagrams that model and cartography aspects of the evolving cosmos.
We demonstrate that these transitions in cosmologies and their accompanying cosmographies can be explained in correlation with advances made in how we, as a species, have mastered knowledge on the nature of matter, space and most of all time. How we understand matter, space and time (ontologically) in turn depends upon how we conceptualize and calculate the latter (epistemologically) from within cultural traditions including scientific ones, and by making use of natural and mathematical languages. For these reasons, cosmologies impact how we define causality, and we will examine how and why our notions on causality have transitioned from being understood as cyclical to linear to mechanical and multidirectional.

In what follows, we outline these different cosmologies and cosmographies and focus in particular on how they define time and causality differentially. While this by and large implies an analysis of philosophical and scientific thought, and though I am a philosopher of science, this paper is also written from within my background as a comparative cultural anthropologist. This means that my aim is to compare and thereby understand the differences between the cosmologies and to outline their historical trajectories, more than it is to represent them from within the specific doctrines involved. Given the large scope of this article, it is also not my aim to give full details on the various doctrines involved, but to find their underlying structures and the transitions they underwent.

\section{The Intellectual Structure of Greek Cosmologies}

Cosmologies explain the nature of existence by providing theories on matter, space and time. Western cosmologies still track back to those of the ancient Greeks that commence with the writings of the pre-Socratics and that culminate with the works of Plato and Aristotle. I will focus on these latter two scholars, and I will do so extensively, because they were the most influential for intellectual thought as it would develop in Judeo-Christian

Table 1 Summary of the four transitions in the intellectual history of western thought, their different notions of time and their associated concepts of causality

\begin{tabular}{|c|c|c|c|c|}
\hline Cosmology & Ancient Greeks & Judeo-Christians & $\begin{array}{l}\text { Classical physics and } \\
\text { natural history }\end{array}$ & $\begin{array}{l}\text { Modern physics and evolutionary } \\
\text { biology }\end{array}$ \\
\hline Cosmographies & $\begin{array}{l}\text { Wheels of time and } \\
\text { chains of being }\end{array}$ & $\begin{array}{l}\text { Scala naturae and } \\
\text { timelines }\end{array}$ & Timelines and trees & Trees and networks \\
\hline \multirow[t]{2}{*}{ Time } & $\begin{array}{l}\text { (Once created) eternal } \\
\text { and circular/cyclical }\end{array}$ & $\begin{array}{l}\text { Cosmogonic and } \\
\text { eschatological }\end{array}$ & Linear and multi-linear & $\begin{array}{l}\text { Inexistent or multiple } \\
\text { and multi-directional }\end{array}$ \\
\hline & $\begin{array}{l}\text { True versus relative } \\
\text { time }\end{array}$ & $\begin{array}{l}\text { Eternity versus } \\
\text { created/numerical } \\
\text { time }\end{array}$ & $\begin{array}{l}\text { Absolute (mathematical) } \\
\text { versus relative time }\end{array}$ & $\begin{array}{l}\text { Space-time versus geological, } \\
\text { chrono-biological and phenomenological } \\
\text { versus numerical time }\end{array}$ \\
\hline Causality & Cyclical teleology & $\begin{array}{l}\text { Chronological, non- } \\
\text { uniform teleology }\end{array}$ & Mechanical, uniform teleology & $\begin{array}{l}\text { Statistical probabilities } \\
\text { and uncertainties }\end{array}$ \\
\hline
\end{tabular}


cosmologies of the Middle Ages, and their influence well extends to the rise of Natural History Research.

Although Plato and his student Aristotle vary in their teachings in great detail, both share a basic intellectual structure whereupon they build their cosmology. This basic intellectual structure has precursors in non-Western cosmologies which we do not discuss in this section but we will briefly mention them in the next. Instead, here we focus on how the common structure defines their notions on time and causality.

Firstly, this common structure involves a distinction between the non-existent, that what exists temporarily, and that was exists permanently. In his Metaphysics, Aristotle (2012), for example, distinguished between the realm of non-being (what we would call nothing), the realm of coming and becoming (earth and its inhabitants that undergo constant change), and the metaphysical realm of (permanent) being that include celestial bodies (planets and stars) and his notorious unmoved mover. Aristotle based his views on the works of Plato (1960, Timaeus 27d-28a) who in turn built upon the Ionic philosophers when he distinguished between "that which is existent always and has no becoming" (the permanent or that which never perishes) and "that which is becoming always and never is existent" (the temporal that undergoes constant change and therefore never really is), both of which he argued were preceded by chaos (nothing).

Secondly, nothing, or that what does not exist, is called "chaos" and chaos precedes both the permanent celestial beings and the changing earth that originate from chaos (Timaeus 30a, 37d). This implies that although chaos is no-thing, it does exist as an "unformed" substance wherefrom the permanent and temporal, which are both structures in time, originate. Nothing or the inexistent, however, neither lies in the past nor the future. Although chaos precedes timely things, chaos itself is timeless. Instead, chaos is conceptualized as a disordered or unformed state of matter and chaos is distinguished from order $(\log o s)$. Both the realm of the temporal and the eternal are conceptualized as ordered structures, mostly because they have a form or structure.

Thirdly, the cosmos or universe and its inhabitants are said to be ordered because they are distinguished into matter and space. Matter is described in terms of the four elements, fire, air, water and earth that roam in place or space, which can be considered the fifth element (Plato, Timaeus 58d). We first turn to their concept of matter and then to their concept of place or space.

All matter is made up of the elements that recursively, and in less or purer form, make up the various layers of the cosmos. Inspired by the atomistic schools of the fifth century BC that theorized that all wholes are made up from discrete parts, for Plato (Timaeus 31b-32c), the cosmos on a macroscale, and recursively earth on a mesoscale, is a solid living body made up of the elements on a microscale. Fire and earth give visibility and tangibility, and air and water become intermediary binding elements with "air being to water as fire to air, and water being to earth as air to water". According to Aristotle, the elements also have temperaments or temperatures, earth is cold, fire is warm, water is wet and air is dry. Plato (Timaeus 53c-56) states that all elements are made up of solid bodies where "depth should be bounded by a plane surface; and the rectilinear plane is composed of triangles ...". The different elements originate through a different combination of pyramids and they can somewhat transform into one another (e.g. water can boil and evaporate). Fire is a tetrahedron, earth is a cube, air an octahedron, and water an icosahedron, and today we know these three-dimensional structures as the platonic solids. All planetary bodies on a macroscale, and all earthly substances on a mesoscale are "ordered" or made up from these microelements, and humans can understand this order through the science of geometry.

The distinction of the cosmos into a micro-, meso- and macro-cosmos does not follow a linear or rigid hierarchy where things get added one after the other. Rather, substances are recursively embedded Russian dolls that can be purer or less composite than others. In association, they are more or less enduring in time. All earthly bodies, for example, perish, while the celestial bodies are thought to be made of purer elements, and their bonds, for Plato, can only be broken by the demiurge who made them in the first place. And without a second law of thermodynamics, there is no energy expenditure, so the substances merely break down to their microelements that return to chaos until they reshape or reincarnate into different solid bodies. Bodily substances in turn are distinguished from a pure intellect, one that has no body and that therefore remains permanent.

As said, the four elements roam in place or space, to which we now turn. For Plato (Timaeus 52b), place "provides room for all things that have birth ... for ... it is somehow necessary that all that exists should exist in some spot and occupying some place, and that that which is neither on earth nor anywhere in the Heaven [outer space] is nothing". Place and space are thus the locus where matter roams, and this locus can be conceptualized both as inner, earthly place (the mesocosmos) and outer space (the macrocosmos). Place enables substances to exist on a micro- and mesoscale, and on a macroscale, in outer space and from within their geocentric worldview, we find earth in the middle followed by the celestial bodies that are presumed to orbit in perfect circles around it.

Place and space therefore also consort with ether which is considered the purest element of air that fills space thereby enabling movement of matter. In Greek mythology (Decaen 2004), "ether" is both a deity and a substance that 
brings forth the "brightest" light; it coincides with the upper layer of the atmosphere where it provides the "purest" air to (other) deities that reign in "heaven" or outer space; and with Plato and Aristotle, it becomes associated with the crystalline substance that bounds the planets to their orbits around the earth as well as the less perfect substance that enables movement of everyday objects in place. For those reasons, ether, in ancient Greece and the Middle Ages that would follow, is often conflated with air (and later with fire) leading to theorizing on not five but four elements.

The outer boundary of space coincides with the zodiac. And this ancient universe is represented by the fifth Platonic solid which is often interpreted as the dodecahedron, although Plato never gives a specific name. In the most common interpretations, the dodecahedron has 12 faces that each form a perfect pentagon, but these pentagons can also be understood as pyramid- or stellar-like (as is the case in the pentakis and stellated dodecahedron). According to Plato, the demiurge "used it up for the Universe in his decoration thereof".

Fourthly, all order in the cosmos is temporal because all solid bodies (can) perish (with or without the intervention of Plato's demiurge, who according to him can make and break the celestial bodies). The cosmos thus undergoes constant change (or it has the potential to do so) and all change is defined as the motion or movement of matter (earth, fire, water and air as well as the earthly and celestial substances they form) in place or space (the fifth element).

Starting with the micro-elements, these all have a designated place in the cosmos to which they move "naturally". For Aristotle (2012, Metaphysics, Book 12, 1073b1-1074a13), earth naturally moves to the center, water to the surface, air to the sky, and the air/sky are followed by fire and ether. On a macro-scale, the living planets' place (understood both as locus and goal) is to orbit in perfect circles around the earth (facilitated by ether), and they do so each at their own rhythm or pace in what Plato (Timaeus 37a-38e) calls the Circle of the Similar. This circle is "similar" to what he calls the Circle of the Same, which refers to the sidereal sky that contains the wheel of the zodiac.

The zodiac literally translates as the circle/cycle or belt/ chain of animals, and it is thus in this context of celestial motion that we find the first use of Chains of Being. The zodiac and the planets, for Plato, all stay in course with destiny and necessity because the demiurge has "chained" or formed "a living bond" of them which only the demiurge can break, and he has defined and informed them of their proper duties, which involve their rotations.

On a meso-level, things become more complicated. Most earthly substances are composite and thus made up of different elements that each "want" to "move" to their different natural places in the cosmos which causes for conflict. In addition, when matter is not moved "internally or naturally" according to its harmonious place in the cosmos, it is moved by external force (either purposefully or accidentally), and such movements also cause for conflict.

Nonetheless, here too there exists a Chain of Being that, according to Aristotle (History of Animals, 588b:4-14 in Barnes 1984), ties all substances together into "a continuous scale of ascent". This scale of ascent goes from lifeless and inanimate matter to the beings with a vegetative, animistic and intellectual soul and shows the degree of perfection a substance possesses (for a discussion see Gontier 2011). Bodies however remain fixed. At most, they have the potential to reach their final goal in harmony with their end place (a human body can mature and reach old age, for example, and it can develop its intellect to the highest form of perfection). This scala naturae as the Latins would call it, for the Greeks is therefore merely an assessment, or if one wishes, a non-evolutionary systematic classification of the types of "souls" there are, and "perfection" is used as the criterion by which such classification occurs.

What is more important, is that all bodies that make up the Chain of Being are in turn bounded or chained by the inevitable and predestined Cycle of Coming and Becoming. Microelements order into substances and when these substances perish they return to chaos until they underlie the formation of new substances. On a meso-level, plants and animals grow, flourish and die and their offspring does just the same. And on a macroscale, planets are chained to their orbits, returning to their original starting position every end of their particular cycle. This recurring and circular cycle or chain of events, which in subsequent cosmologies would be called the linear succession of matter in motion, defines causality, and for the Greeks, this chain follows an inevitable cycle of coming and becoming, a cycle that regenerates or reincarnates over and over again.

In sum, there are, roughly, two types of movement, one natural and internal, and one unnatural and external. The natural movement of substances or bodies follows the predestined and inevitable cycle of coming and becoming, and elements have an "inner" calling and a "wanting" to return to their natural and designated place in the cosmos (what Aristotle calls the formal and final cause to which we return later). External movement is any movement induced by extraneous force on an object. The cosmos is in constant flux, and any change is defined as the movement of matter in place or space. All movement in turn, is considered to follow a predestined, regenerating and reincarnating cycle or chain of events: the cycle of coming and becoming and the circular return of the planets and the stars to their 
original positions in the Cycles of the Similar and the Same.

Fifthly, as said, cosmologies define matter, space and time and it is through their theories of motion that Plato and Aristotle defined time. As we saw, any movement or motion of matter in place or space occurs in a cyclic timely fashion. From their geocentric worldview, the cycle of the sidereal stars define (the hours of) night and day; the moon's cycle defines the Greeks' lunar monthly calendar; and the sun's (apparent) counterclockwise movement through the zodiac (the ecliptic or what he calls the Revolution of the Other) defines a yearly cycle (Plato $T_{i-}$ maeus, 37e-39c).

Plato (Timaeus, 39c) noted that: "Of the other stars the revolutions have not been discovered by men (save for a few out of the many); wherefore they have no names for them, nor do they compute and compare their relative measurements, so that they are not aware, as a rule, [39d] that the "wanderings" of these bodies, which are hard to calculate and of wondrous complexity, constitute Time." And by time here he meant relative time, a time that, in his epistemology, brings forth mere opinions (doxa) that oppose true knowledge (episteme). He continued this passage by noting that "Nevertheless, it is still quite possible to perceive that the complete number of Time fulfils the Complete Year when all the eight circuits [Earth, the Moon, Mercury, Venus, the Sun, Mars, Jupiter and Saturn], with their relative speeds, finish together and come to a head, when measured by the revolution of the Same and Similarly-moving." True time then, for Plato, accords with the Complete Year, the grand cycle that recommences when all different cycles realign to their original position. Today we call it the Platonic year.

The ancient Greek differentiation between relative and true time is thus mainly due to the earth's wobble around its own axis, the precession. Viewed from earth, it makes the pole star, the equinoxes, and the zodiac wheel shift over time. All planets have such a precession and stars have proper motion too. Whether and which precessions were known to Plato and Aristotle is uncertain, but they knew of the consequences of Earth's precession: the zodiac shifts over time until it reaches its original starting point. For Plato, the complete cycle corresponds with the (hypothesized) exact alignment of all cycles to their original position, and the cycle of this complete year is assumed not to undergo change, instead it repeats for all eternity. For that reason, it correlates to true time, and any knowledge of this cycle, for Plato, corresponds to true episteme. Consequently, relative time is given a mere numerical value, e.g. year $1,2,3, \ldots$ of a bigger repeating cycle. And all times are conceptualized as circular motions.

Nonetheless, though both Plato and Aristotle agree that the complete cycle corresponds with true time which is conceptualized as circular and eternal, and all other cycles with relative time, they disagreed on the nature of time itself. For Plato, time comes into being when the demiurge molds time as a copy or imitation of eternity, but for Aristotle, time has neither beginning nor ending and thus corresponds with eternity.

Time is circular for Aristotle because if we think of any moment in time, we think about what was before or what comes after, and thus we continue thinking about time. For Aristotle, such continuity demonstrates circularity. Any and all thinking on beginnings and endings are furthermore only made possible because there is time.

But it is impossible that movement should either have come into being or cease to be (for it must always have existed), or that time should. For there could not be a before and an after if time did not exist. Movement also is continuous, then, in the sense in which time is; for time is either the same thing as movement or an attribute of movement. And there is no continuous movement except movement in place, and of this only that which is circular is continuous. (Aristotle, Metaphysics XII, 6)

Time is either identical to movement (of matter in space) or an attribute thereof and in a specific reading of Aristotle, the unmoved mover or primary cause can even be understood as true or eternal time. It is true time (as a metaphysical constant) that therefore moves or causes all motion of matter in the cycle of coming and becoming that underlies his "great chain of being".

For Plato on the other hand, the bodiless eternal being stands above and beyond time, an idea that would later be adopted by Judeo-Christian religion. Or as Plato (Timaeus 37e-38a) said it:

For simultaneously with the construction of the Heaven $\mathrm{He}$ [the demiurge] contrived the production of days and nights and months and years, which existed not before the Heaven came into being. And these are all portions of Time; even as "Was" and "Shall be" are generated forms of Time, although we apply them wrongly, without noticing, to Eternal Being. For we say that it "is" or "was" or "will be," whereas, in truth of speech, "is" alone [38a] is the appropriate term; "was" and "will be," on the other hand, are terms properly applicable to the Becoming which proceeds in Time, since both of these are motions; but it belongs not to that which is ever changeless in its uniformity to become either older or younger through time, nor ever to have become so, nor to be so now, nor to be about to be so hereafter, nor in general to be subject to any of the conditions which Becoming has attached to the things which 
move in the world of Sense, these being generated forms of Time, which imitates Eternity and circles round according to number.

\section{Time and Causality for the Ancient Greeks}

Both Aristotle and Plato argued that all becoming or motion of matter proceeds in time, and time, as the last citation said, circles round according to number. Plato says that human intellects can come to know and participate in these numbers. In this part we analyze just what kind of number system he applied. By taking the zodiac as an example, we first demonstrate that the ancients calculated both true and relative time from within the sciences of geometry and trigonometry, both of which affiliate with a more ancient sexagesimal counting system (a number system that has 60 as its base). Secondly, we describe the genealogical roots of the sexagesimal system and detail how it was replaced, or better reduced, to the decimal counting system. Thirdly, we hone in on how the sexagesimal counting system explains the ancients' ideas on causality.

1. In his Timaeus, Plato (1960) points out that in Greek mythology Uranus (sky) and Gaia (earth) give birth to Krónos (relative or numerical time understood as tempo which means both speed and weather) that gives birth to Zeus (day). Krónos is the deity from which we lend the word chronometry or timekeeping, and he associates with the last planet before the zodiac, Saturn. Krónos is therefore often depicted with agricultural tools such as the sickle and scythe, because knowledge of the zodiac lends insight into the yearly seasons and this enables successful farming. Temporal time is distinguished from Aeon (not mentioned by Plato) that represents true time or eternity.

Plato could think of no reason to disbelieve his ancients in what regards the origin of time, and he subsequently argued that his demiurge distinguished between the circle of the same and the similar, the stars and the planets. Relative time, understood both as speed and weather, is derived from celestial motions, and for Plato these motions are knowledgeable through number, and applicable only to all that becomes in time (the motion of matter in space), because the eternal being stands above and beyond it.

Plato goes no further, but how then, did the ancients calculate time (Macey 1989; Chrisomalis 2010; Rudman 2007)? From within their geocentric worldview, the rotation of the stars defines night and day that, idealized and on the days of the equinoxes, contain 2 times $12 \mathrm{~h}$ made up of $60 \mathrm{~min}$ made up of $60 \mathrm{~s}$. Hours, minutes and seconds, even today, remain depicted by a $360^{\circ}$ circle that is divided into 12 equal parts. The moon cycle defines the months which for the Hellenics are sidereal while in the later Julian calendar they are synodic (Samuel 1972). A sidereal month contains roughly two times 14 days each divided into 4 phases and there are 13 such cycles in a year of 364 days. But such numbers are too "unlucky" or "imperfect" and in line with the $360^{\circ}$ circle, months become rounded up into 2 times 15 days and reduced to 12 (which roughly corresponds to the synodic months) which makes for 360 days. And each month corresponds with one of the 12 zodiacal signs.

The zodiac in turn defines an idealized 360-day long year. The tropical zodiac (Gingerich 1984) is entirely based upon the-for viewers in the northern hemisphere counterclockwise, and for viewers in the southern hemisphere clockwise-apparent movement of the sun (the ecliptic) around a geocentric earth. This movement too is thought as a perfect cycle and thus as a full $360^{\circ}$ circle. The Sun's movement is tracked in relation to the 12 zodiac signs that it runs through over the year, and these signs correspond with stellar constellations that are formed from connecting distinct stars to one another by imaginary lines. One zodiac sign represents one month, and a new zodiac sign is said to begin when the sun enters the sign (e.g. point 0 of the perfect circle marks the beginning of Aries and point 30 is point 0 for Taurus). Accordingly, the circle is divided into 12 equal parts, each separated from one another by $30^{\circ}$, and each month lasts exactly 30 days, and $1^{\circ}$ represents one day. The zodiac also aligns with the equinoxes (point zero of Aries and Libra) and the solstices (point zero of Cancer and Capricorn) and thus with the 4 seasons that we distinguish in the west.

Western astrologists furthermore divide the 12 signs in three ways, always beginning with Aries (Fig. 1). Duplicity-wise, they attribute a male and female status to each sign; triplicity-wise they divide the signs into cardinal, fixed and mutable signs; and quadruplicity-wise they add the four elements (fire, earth, air and water), and they do so for all signs in a repetitive and alternating way. When we draw lines between the genders, we obtain two perfect hexagons ( 2 times 6 ); connecting the triplicities we obtain three perfect squares ( 3 times 4$)$, and linking the same elements brings forth four perfect triangles (4 times 3 ). All form dodecagons (12-sided polygons) and when we add volume and combine either the fourfold triangles, the threefold squares or the twofold hexagons, we obtain dodecahedrons where the element-based one for Plato represents the entire universe.

The zodiac year, the months and hours are all understood as perfect circles or wheels, and all are highly abstract, idealized and complete models of how the ancients understood tempo. They are idealized numbers because, from within their actual time measurements, the ancient Greeks and later also the Romans were already much closer to the actual times that these phenomena take (Macey 1989). Following the Egyptians, both already lived 


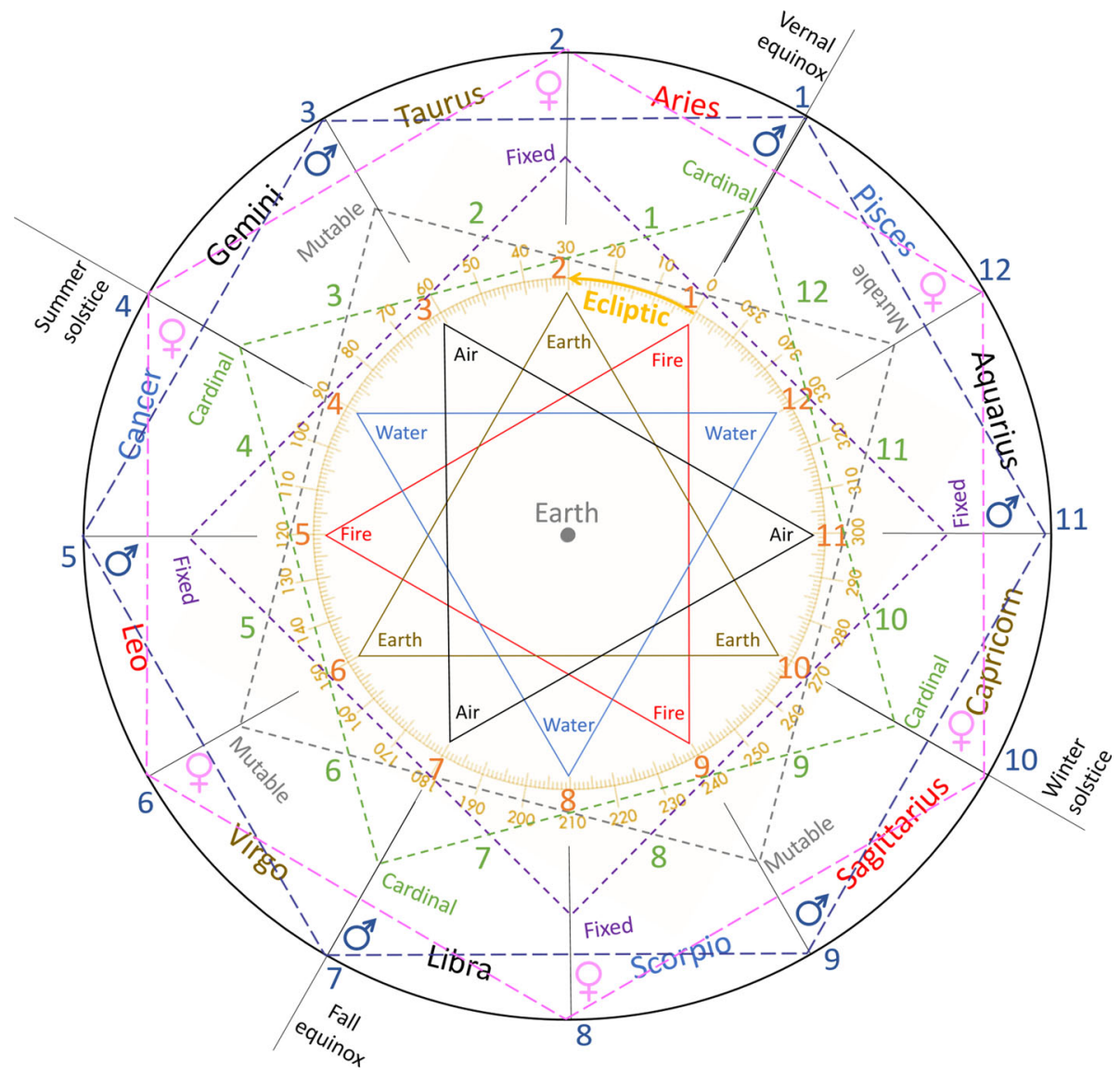

Fig. 1 An abstraction of the "perfect" tropical zodiac. The zodiac defines a yearly cycle and marks a four-seasonal alignment in line with the equinoxes and solstices. The zodiac begins in Spring when, from a geocentric worldview, the ecliptic (or apparent movement of the sun) touches the celestial equator; and that moment is set to align with point zero of Aries. Duplicity-wise, Aries, Gemini, Leo, Libra, Sagittarius, and Aquarius are masculine signs (in dark blue); Taurus, Cancer, Virgo, Scorpio, Capricorn and Pisces are feminine signs (in pink). Triplicity-wise, Aries, Leo and Sagittarius are Fire signs (in red); Taurus, Virgo and Capricorn are Earth signs (in brown); Gemini, Libra and Aquarius are Air signs (in black); and Cancer, Scorpio and Pisces are Water signs (in light blue). Quadruplicity-wise, Aries, Cancer, Libra and Capricorn are cardinal signs (in green); Taurus, Leo, Scorpio and Aquarius are fixed signs (in purple); and

in a 365 instead of 360-day long years. The Greek empire never had a uniform calendar, and not all months had an equal (30-day long) duration, and their calendar remained based upon the moon cycle, with some provinces intercalating an extra 13th month.

2. Where then, do these idealizations come from? The above italicized numbers all have a prominent meaning in the sexagesimal number system that take 60 as its base. The number 60 is what mathematicians today call a superior highly composite number. The number 60 can be decomposed into 12 factors $(1,2,3,4,5,6,10,12,15,20$, $30,60)$ and it has 3 prime numbers. Besides 60 , other such superior highly composite numbers are 2, 6, 12, 60, 120,
Gemini, Virgo, Sagittarius and Pisces are mutable signs (in grey). Duplicities connect into two perfect hexagons, triplicities form four perfect triangles, and quadruplicities lead to three perfect squares. Each of the three dodecagons is the middle of a three-dimensional dodecahedron. For Plato, the dodecahedron represents the perfect universe, and it is obtained via the triangles that represent the elements. The squares and hexagons are older means to represent the beginnings and endings of the 12 positions of the zodiac. The hexagons, for example, correspond with the six seasons that each last 2 months in the Vedic Zodiac. The squares are probably of ancient Egyptian origin. Materialized, these shapes were perhaps used as turntables to obtain and predict the positions of the signs and thus the tempo (understood as weather)

360 , etc. and these numbers too have prominent roles in a sexagesimal system. The system is older than the decimal one and was developed by both Mesopotamian (Egyptian and Babylonian) and ancient Vedic peoples from at least the 3rd millennium BC onward (Neugebauer et al. 1945; Rudman 2007). And these populations share common linguistic and genetic roots (Cavalli-Sforza 2000; Kuzmina 2007).

In the sexagesimal number system, the symbols and numbers 1 through 9 are there, but this does not yet establish a decimal system, because originally the number zero was lacking. When exactly this number was first introduced is unknown, but evidence suggests that 
Egyptians used it from around the 2nd millennium BC (Gheverghese 2011), Babylonians left a void space from 700 BC (Kaplan 2000), and first written evidence for Vedic usage of the number zero dates to only $300 \mathrm{BC}$ (Ôhashi 1993; Plofker 2009: 56). All cultures precede the Greeks, but Plato is estimated to have written his Timaeus around $360 \mathrm{BC}$, so before the Vedic used the number 0. First written evidence however seldom associates with actual introductions of ideas or notational systems.

Certain is that the ancient Greeks in general did not apply the number zero in their alphabetic number system (Chrisomalis 2010), not because they had no knowledge of it, but because they questioned its validity, by asking how nothing can bring about something. Plato (Timaeus 30a, 37d) and Aristotle (with his description of how unformed or disordered matter is turned into an ordered structure through the material and formal cause), on the other hand, took as a given that nothing or chaos precedes order. So while perhaps not accepted in mainstream Greek thought, there is no reason to assume that philosophers were not aware of more ancient sexagesimal number systems and the associated knowledge they provide on the tempo (speed and weather), the zodiac and the hypothesized complete year. The Romans did use the number zero, and also had significantly more contact with Egypt than the ancient Greeks did (although there was contact); as did Ptolemy (Ashmand 1822), who introduced the tropical zodiac as we know it, thereby continuing to apply a sexagesimal number system. So the question remains how much the ancient Greeks new about it, and answers might be found in sketching the genealogy of the zodiac.

The tropical zodiac finds its origin in Mesopotamia while the Vedic developed a sidereal zodiac (Pingree 1981; Ôhashi 1993, 2014; Rogers 1998). Both make use of exactly the same signs that are based upon the same stellar constellations, and these were also known to both the Greeks and the Romans (Schaefer 2006).

Drawing the dodecagon by means of duplicities, triplicities or quadruplicities makes us enter the realm of magic or sacred geometry. Such geometry can be purely diagrammatic and thus number-free, and such shapes can and most likely were also studied through cymatics or the study of sound waves. But when looking for perfection, any associated calculations were made from within trigonometry which was originally formulated in a sexagesimal number system.

Geometrical configurations such as triangles and squares feature prominently in Egyptian artworks, and hexagons, dodecagons, and dodecahedrons are hallmarks of Vedic mandalas. In Vedic cosmology, timekeeping is one of the vedānga or accompanying sciences of the Vedic scriptures (Lochtefeld 2002), and timekeeping is defined as astronomy or astrology. The various sections of the Rg-Veda
(Griffith 1896) are called mandalas, which is Sanskrit for circle, and mandalas or wheels of time are typical cosmographies of Hinduism as well as its later derivatives such as Buddhism, Taoism and Confucianism. Here, in correspondence with the introduction of the number 0 , which for the Vedic corresponds with the fifth element (void or what we call ether), and with the eternal repetition of the cycles, it guides their ideas on reincarnation.

In the Vedic sidereal zodiac (Pingree 1973, 1981; Ohashi 2014; Vahnia and Yadav 2011), a $360^{\circ}$ circle is made up of 6 times $60^{\circ}$ that align with their not 4 but 6 seasons that are represented by the hexagons: spring, summer, monsoon, autumn, prewinter, winter. These are represented by not one but two hexagons because seasons shift over time due to the precession (ayanāmiśa). Also due to the precession, zodiacal signs shift over ages (a word that for us lends its name from the Greek deity Aeon that associates with true time). Spring, for example, used to be in the Age or Aeon of Aries, currently it is in the Age of Pisces and in the future it will be in the Age of Aquarius). The shift from one sign to another is calculated as 6 seasons times 360 days which equals to 2.160 years. This latter number, times 12 signs gives 25.920 years which equals the amount of time it takes to complete the cycle of the zodiac, what we call the Platonic great year. Or, calculated differently, every 72 years (6 times 12), the equinoxes and the zodiac shift with $1^{\circ}$, and 72 times 360 equals 25.920. NASA currently calculates the Platonic year to be 25.800 years, so the Vedic came very close.

Contrary to the tropical zodiac, the sidereal zodiac (Fig. 2) thus takes the precession into account. Accordingly, the vernal equinox occurs in Pisces, but when their system first became introduced, it occurred in Aries. Aries marked not only the beginning of Spring but also the beginning of the New Year which was an adaptation from Holi or the Spring and New Year festival that was calculated based upon the moon cycle.

The tropical zodiac as we know it in the west does not take the (consequences of the) precession into account and aligns the vernal equinox straightforwardly with point 0 of Aries, so the system remains fixed over the ages.

Also different is that for most of the Greek provinces the year does not start in Spring, rather it ends with the beginning of Winter. To understand this shift we need to go to Mesopotamian writings. The tropical zodiac is often considered a neo-Babylonian invention that became introduced around $700 \mathrm{BC}$, but we find the first written evidence of knowledge of a zodiac in early Mesopotamian writings. The Enûma Eliš (King 1902) is a creation myth written on clay tablets dating to $1.100 \mathrm{BC}$ while the story is thought to be at least a 1.000 years older. It describes how Marduk (Jupiter, the second farthest planet in ancient cosmologyor at that time perhaps thought to be the last one before the 
Fig. 2 The difference between the sidereal (green/above) and tropical zodiac (brown/below) as seen from a geocentric earth. The tropical zodiac is entirely sun-based and the signs are set upon the ecliptic. The sidereal zodiac is based upon the position of the sun in relation to the star constellations as they appear in the night sky (measured in the early morning when the sun rises). The tropical zodiac aligns the spring equinox (the point where the ecliptic or apparent position of the sun touches the celestial sphere) straight onto point 0 of the tropical Aries, and the summer and winter solstices fall perpendicular upon it, respectively right between Gemini and Cancer and Sagittarius and Capricorn. The earth wobbles and therefore tilts around $23.5^{\circ}$ from the equator, which causes for a $1^{\circ}$ shift over a span of 72 years. Measured against the sidereal zodiac, this causes for the spring equinox to be $5 \mathrm{~s}$ early every year, a phenomenon called precession. The Vedic had good knowledge of the precession and took it into account when measuring the vernal equinox. The tropical zodiac does not, and since its adoption the vernal equinox is therefore fixed in Aries (the image is based on http://www. vedicastroyoga.com/learn/ vedic-vs-western/) (Color figure online)

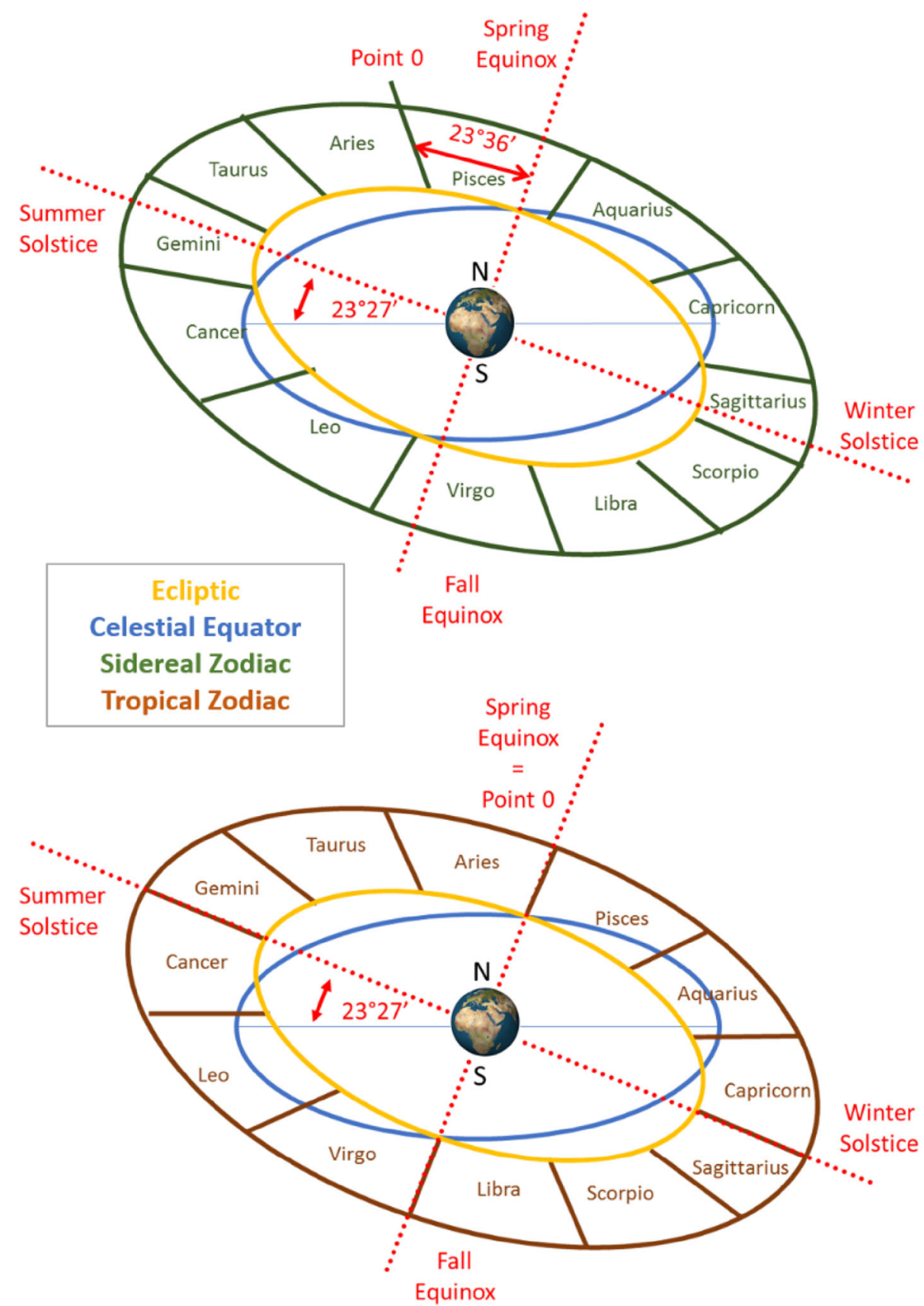

zodiac) successfully saves other agents (deities mothered by the chaotic couple Apsu/cosmic water or sky/space and Tiamut/earthly water)—from being killed by 11 monsters created by Tiamut in revenge for the gods (their children) putting Apsu to sleep (because he in turn wanted to kill them because they made too much noise-the story of Babel). With bow and arrow (Sagittarius/Jupiter), Marduk slays the 11 "monsters" that include the Scorpio man, fishman (Pisces) and ram (Aries), but also creatures such as snakes and a dragon, and places them in the night sky where, chained forever at his feet, they serve the humans to calculate time (Table 2). Some of the 11 monsters to this day remain unidentified, but those that have appear to be a mix of signs that belong to the tropical, Egyptian (Dendera), sidereal and even the Chinese zodiac.

Marduk is considered the Babylonian king of mankind and the maker of the calendar. He also affiliates with the planet Jupiter, that "rules" over the Sagittarius constellation, the bow and arrow man. And because Sagittarius is said to rule over the 11 chained signs, he can be interpreted to represent the 12th (and thus 1st) sign that marks the beginning of the Babylonian new year. This is because the Sagittarian sign associates with the period wherein the winter solstice occurs (sometime between 21st and 23rd of 
Table 2 Extract from Tablet 5 of the Enûma Eliš

He (Marduk) made the stations for the great gods; The stars, their images, as the stars of the Zodiac, he fixed. He ordained the year and into
sections he divided it; For the twelve months he fixed three stars. After he had... the days of the year... images, He founded the station of
Nibir [the planet Jupiter] to determine their bounds; That none might err or go astray, He set the station of Bel and Ea along with him. He
opened great gates on both sides, He made strong the bolt on the left and on the right. In the midst thereof he fixed the zenith; The Moon-god
he caused to shine forth, the night he entrusted to him. He appointed him, a being of the night, to determine the days; Every month without
ceasing with the crown he covered him, saying: "At the beginning of the month, when thou shinest upon the land, Thou commandest the
horns to determine six days, And on the seventh day to divide the crown. On the fourteenth day thou shalt stand opposite, the half.... When
the Sun-god on the foundation of heaven...thee, The... thou shalt cause to..., and thou shalt make his... unto the path of the Sun-god shalt
thou cause to draw night, And on the... day thou shalt stand opposite, and the Sun-god shall... to traverse her way.... thou shalt cause to
draw nigh, and thou shalt judge the right.... to destroy....... They praised the work which he had done... Then Anu raised the... in the
assembly of the gods. He kissed the bow, saying, "It is...." And thus he named the names of the bow, saying, ..Long-wood' shall be one
name, and the second name shall be..., And its third name shall be the Bow-star, in heaven shall it....".

The ellipses are not mine, they mark lost fragments (translated by King 1902)

December), which in many middle eastern and western cultures is accompanied with celebrations such as the Hebrew Hanukkah (festival of lights), the ancient Roman feast of light (Sol Invictus), the Christian Christmas or the Germanic Yule that all mark the beginning of a new yearly cycle.

Precession or at least the phenomena associated with it also appear to have been known already by the Egyptians, who divided 360 with the $1^{\circ}$ of precession that occurs every 72 years, which made them obtain the 5 extra days they added to the 360-day calendar in order to obtain a full year (Sellars 2007: 138-163). And besides their fascination with triangles, it were also these scholars that linked the square (the remaining geometric shape in the depiction of the tropical zodiac) to the four winds as well as the four elements.

Sketching the exact genealogy of zodiac systems remains difficult and we also do not know to what extent the ancient Greek philosophers knew about this genealogy. Common knowledge states that the tropical zodiac reached the West through the works of Hipparchus, a Hellenic Greek that lived in the second century BC and thus 200 years after Plato, and Hipparchus is usually attributed to having invented trigonometry. Ptolemy (Ashmand 1822), a Greco-Egyptian who finalized the tropical zodiac as we know it in his Tetrabiblos, a companion to his $\mathrm{Al}$ magest, did so only in the second century $\mathrm{AD}$ but by continuing to use the sexagesimal number system.

It is nonetheless certain that the Greeks maintained contact with ancient Egyptian/Mesopotamian and Vedic cultures. In Egyptian mythology, for example, it was Thoth (Sellars 2007), the spokesman of the Sun God Ra, and the deity associated with the moon, the calendar, and sciences involving language, reason, and numbers, that made the lucky gamble to add 5 extra days. This deity became known to the Greeks as Hermes, and his knowledge was written down in magical works such as the never found "Book of Thoth" as well as in more material and today fragmented works that include the Kore Kosmou or Virgin of the World, i.e. Hermetic writings that detail Egyptian cosmologies that are preserved in ancient Greek only. Alexander the Great, a student of Aristotle, is also known to have brought Vedic knowledge to Europe, but there is no reason to assume there did not exist previous knowledge exchange. And some of the numbers specifically mentioned by Plato, such as the ideal amount of people that make up a republic, correspond to prominent numbers in the sexagesimal number system. So both Plato and Aristotle must have known about these ancient worldviews, however fragmented their knowledge might have been.

It is therefore safer to assume that when it is said that the ancient Greeks (Plato, Aristotle, Euclid, Hipparchus, and the Greco-Egyptian Ptolemy) developed either geometry or trigonometry, what is meant is that they steadily started to reduce the sexagesimal system (base 60) that underlies ancient cosmologies to the decimal system (base 10) that forms one branch of it (Chrisomalis 2010). Such explains, for example, why especially Ptolemy (Ashmand 1822) would favor Aristotelian research into the causes and temperaments of the elements, the celestial bodies and the zodiac, instead of deducing weather predictions or horoscopes from the sexagesimal meanings attributed to numbers.

In any case, the zodiac, time and temperament or horoscopes were thus originally formulated in a sexagesimal number system. And this number system, through the associated sciences of geometry and trigonometry, underlie the ancients' ideas on cyclic time. Knowledge of the zodiac thereby enabled the biggest invention of humankind: successful farming due to predictive knowledge of the tempo. In this regard, it is intriguing that dodecahedrons, presumably the fifth Platonic solid, and shaped in such a way that the faces form pentagons, only become wide-spread material artifacts found all-over Europe within Gallo-Roman settlements. Here, they have been suggested to function as astronomic measurements of time that helped 
determine sowing and harvesting times (Kurzweil 1956; Nouwen 1993, 1994; Mereaux-Tanguy 1975). Given the gamble weather predictions in northern countries turned out to be, the materialized dodecahedrons were also used as gambling dice.

But regardless of the hard calculations of our ancients, astrology remains an inexact science. This is mainly due to it being on the one hand too observation-based and on the other too theoretical or idealized. If astrology were an exact science, for example, we could simply retro-calculate when point zero of Aries was taken to mark the beginning of Spring, or when (point zero of) Sagittarius overlapped with the winter solstice. It has been attempted (Schaefer 2002) but such remains very difficult, not just because the number systems, and the (amount of months, days, and the length of hours of) calendars have changed, but because such requires a consensus views on when signs begin and how long they last. Not all signs, for example, last exactly 30 days (the sun is in Scorpio for 7 days, for example, and occupies Virgo for 40), and the year does not last 360 days. What is more, the ancients knew this already, and depending upon the rites of a culture they would either add 5 extra uncounted and often considered unlucky days each year, or 15 days each 3 years, or a full month/moonth if deemed necessary to keep in line with their respective seasons. With so much theorizing, we can easily err with 2.000 years or much more when we try to retro-calculate.

3 . We began this paper by saying how cosmologies explain the nature of matter, space and time and suggested that notions on causality are mainly derived from how a particular cosmology defines time both linguistically and mathematically. And in this section we demonstrated that ancient time-keeping associates with a sexagesimal number system. In the sexagesimal system, all numbers from 1 to 9 and later 0-9 are there; and it is a place-value system as mathematicians call it, meaning that each number has its place in an ordered sequence. But not all numbers have an equal importance. Within magic geometry and trigonometry, every number not merely finds its place inside a linear line up, each number also represents a part or moment, a beginning or a conclusion of a small or grand cycle, be it a second, a minute, an hour, a month, a year, or the grand cycle. Some numbers therefore have more meaning than others, as is the case with the number zero, that marks the beginning of a new timely cycle.

In these ancient cosmologies, causality then, is neither defined by things passed nor by things to come. It is true and eternal time on a grand scale, and relative time on a smaller scale, that define the cyclic beginning, (life)course, and ending of all things in the cosmos, and the ancients assumed that time does so beforehand. This enables a teleological worldview where necessity, inevitability and destiny rule, or, where, as Aristotle would demonstrate, the essence of a thing coincides with its final goal, each repeating cycle of change anew.

While the Pre-Socratics were mainly preoccupied with identifying which of the elements came first and how they align in a sequence of order that determines their chain, and while Plato explained most phenomena via his demiurge, Aristotle basically put an end to this theorizing by adding a metaphysical theory of motion to the elements, one that would determine Western Judeo-Christian theorizing on the elements, the planets and their motion well into the Middle Ages. For him, the endlessly repeating cycle is assumed to follow unchanging or permanent principles, i.e. metaphysical causes, reasons or motives (aitia) that inflict change in how matter moves in place and space (Table 3).

The elements that make up matter are stable (the material cause). What changes is the way in which they compose into substances (the formal cause) by internal (harmonious and natural) and external (often conflicting and unnatural) movements or forces (the efficient cause) which underlies the Cycle of all Coming and Becoming. Such motion eventually is driven by the final cause, that coincides with the essence of a substance (the formal cause) and all essences are moved or motivated by the perfection of the unmoved mover. So while things come and go each cycle anew, the form that substances end up taking in a cycle is predetermined by their essence that coincides with their final goal.

Aristotle (Metaphysics V, 2-5) also introduced a perfect bodiless intellect, the unmoved mover, which he understood as the first cause, one that ultimately drives all four causes. And this primary cause that inflicts all change in the repeating cycle stands outside the physical or natural realm (the cosmos), and is part of the metaphysical realm. So while the cosmos is in constant flux, how change occurs (which form things take on, and which place they move to) and the entire directionality of the cycle is predestined and regenerated each cycle anew. And as said when we explained the fifth common structure of the ancient Greek cosmology, in a specific reading of Aristotle, this unmoved mover equals true time.

\section{Judeo-Christian Cosmology and the Rise of Chronology}

The decimal number system is one part of the sexagesimal system (Chrisomalis 2010; Rudman 2007; Macey 1989), and in many ways a simplification thereof, just as the tropical zodiac can be understood as a simplification of the sidereal one. All one needs to do to go from a sexagesimal to a decimal system, is simply take away the magic and keep counting forward. Counting forward makes for a consecutive sequence of numbers where one follows the 
Table 3 Aristotle's causes for the cycle of coming and becoming or the constant and repetitive change of the physical world

1. The material cause

All unformed/chaotic or raw matter is made from the elements that determine the The seed of a flower

inherent and internal movement and potential of matter.

2. The formal cause

The unformed matter's inherent potential: what it can become (the archetypical form The seed has the potential to become a flower

or pattern of something; the end of becoming).

Relates to the definitional what-question on the essence ( $\tau \dot{o} \tau i \tilde{\eta} v \varepsilon v \alpha \iota$ or quidditas)

of something.

3. The efficient cause

The actualization of the potential through external movement (the sources of the change, the "change-producing of the changing", the process of becoming).

The seed becomes a flower through fertile earth, water, sunlight that gives warmth and light, ...

Relates to the mechanistic how-question.

4. The final cause

The goal and function of something, what the potential is actualized for ("that for the The goal or function of the seed is to become a flower sake of which a thing is")

Relates to the teleological and functional what for-question

Some notes: The material, formal and final causes can be understood as internal "movements" or "wantings", while the efficient cause corresponds to external "movement," and all four causal movements eventually are set in motion by the unmoved mover. The formal and final cause also overlap, because the essence of a substance is the same as its final goal

Following Aristotle, scholars have combined these causes with specific research questions. What and what for questions respectively lead to definitional and functional explanations. Both are considered identical and with the rise of Cartesian and Newtonian mechanics, these questions are considered less scientific than the how question. This latter question guides mechanical approaches and thus studies on how objects move by external force

(Aristotle (2008/350 BCE), Physics II, 3; Aristotle (2012/350 BCE) Metaphysics V, 2-5)

other, and in so far as numbers represent numerical time, time becomes one single cycle or a linear series of events. And indeed, cosmographies of the Middle Ages would steadily transform from circles to scales that would come to represent a singular timeline that marks a linear succession of historical events otherwise known as a chronology.

Continuing to count forward is exactly what the Romans, with the introduction of the Roman and Julian calendar did. This calendar was adopted by the early Christians until it was replaced by the Gregorian calendar, an event that happened as late as the sixteenth century. While the Greek cosmologies in many ways trace back to Far Eastern Hindu cultures, the Roman and Julian calendar became introduced after extensive culture contact with the Levant. This contact occurred on the one hand due to Jewish and other refugees coming into Europe from Egypt (the Exodus) and Babylon (the Babylonian Exile) that became under Persian command, and on the other, the reconquering of these places first by Alexander the Great and later by the Roman Caesars (Julius and Augustus), after which they were reconquered by the by then expanding Islam. Unlike ancient traditions, for the Romans, the year commences on January 1st and such a shift marks the true beginning of decimal chronometry. The Roman Julian calendar (established in 46 BC) took for year 1 the hypothesized birth of the city of Rome. In the fifth century, year 1 became associated with the by then hypothesized birth of Jesus (Macey 1989).

Monotheistic religions, for their part, would take away the magic that was associated with the ancient sexagesimal cosmologies, for they would not tolerate any forms of what they call idolatry. These religions, of course, come with their specific calendars, which we will not discuss individually. Suffice to say that the Judaic lunisolar calendar year begins in Spring and ends in Winter; Christians end the year with the bow and arrow man at or around the day the winter solstice takes place in the Julian solar calendar; and the Islamic calendar also used to end with the winter solstice, but because of their calendar being lunar-based, they calculate around 29 days per month, and so their months come a little early each year anew (Macey 1989).

Here we first focus on the genealogy of the Semitic religions and examine how they entertain a cosmological mix between sexagesimal/cyclic-based and linear/decimalbased cosmologies; and secondly we analyze how the adoption of the Roman calendar and the Christianized almanac influenced the rise of semi-religious and semihistorical research known as chronology.

1. In what regards the origins of the three Semitic religions (Judaism, Christianity and Islam), a straight genealogy can be drawn from the Mesopotamian/Babylonian Marduk, i.e. the Jupiter god-king or Sagittarius bow 
and arrow man that binds the monsters of the zodiac at his feet thereby providing time to its peoples, to the Egyptian Sun cult that is centered around Amon-Ra and his spokesperson Thoth, who is the god of the moon, language, mathematics and chronometry (Champollion-Figeac 1832; Pinch 2004). The Greeks associated Amon-Ra with Zeus and Thoth with Hermes (Trismegistus) that affiliates to Mercury. From the Mesopotamians and the Egyptians, a straight genealogical line can be drawn to Persian Zoroastrianism/Mazdeism religion that in particular developed messianistic ideas. All are direct precursors of the three Semitic religions.

Derrida (1981), for example, already pointed out the resemblances there exist between Thoth, the spokesman of $\mathrm{Ra}$, and Jesus, the spokesman of the Christian god. Similarly, Moses is one of the spokesmen of YHWH for Judaism, and the prophet Mohammed is so for Allah in Islam. People kill each other and themselves in the name of these religions, but all worship the same deity, and it is also said so in the different holy books. What differs is the importance they attribute to the different spokespersons: Judaism does not accept Jesus as the new messiah, and Islam recognizes Mohammed as the final prophet.

The Semitic religions in association with the steady adoption of the decimal number system all developed cosmologies that are both cosmogonic and eschatological which means that they describe the beginning of the cosmos that becomes understood as a unique creation act (and what is created is mater, space and time), by a single deity that stands outside creation (and, following Plato, the deity thus stands outside matter, space and time), and they predict the cosmos' equally unique apocalyptic ending. Not only is creation described as a chain or linear sequence of historical events that takes place in time, the holy scriptures moreover provide their revelations by means of a historical narrative. Unique individuals at certain places and in certain moments in time receive specific knowledge on laws that express the rules of behavioral and other conduct, a knowledge that these spokespersons subsequently spread across their peoples.

Judeo-Christian religion thus linearized the eternally repeating cycles into a singular timeline, one that the Christian scholar Eliade (1954: 143) characterizes as "a straight line [that] traces the course of humanity from the initial Fall to final Redemption". In such a view, and different from the ancient cosmologies, Eliade notes that any historical event that takes place in time becomes relevant and of historical interest because of the uniqueness of its character.

It is such thinking that makes chronometrics or the simple measurement of time become chronological, where individual and unique events in time become chained together to explain the origin or beginning, the duration or lifespan, and the ending or apocalypse of the cosmos. And this in turn brings forth a chronological teleology (Table 1), where what happened in the past is held responsible to explain the present and to predict the future. The story of Job, for example, as it is written in the Hebrew Tanakh and the Christian Old Testament (The Bible 1997, Job 14, 5-6), explains how "A man's days are numbered", and how "he cannot live longer than the time You have set," because only YHWH or the Christian god knows the numbers of months a person has to live. Given that a human life is completely determined and predestined to occur at the respective deities' will, their spokespersons detail how to live a virtuous life in the here and now, in order to, like their deity, transcend time by being incorporated into a single and eternal afterlife.

Early Christians also retained practices associated with older sexagesimal systems. When analyzing the ancient Greek, Hindu and other cosmologies, Eliade (1954: 53) noted that it was their notion of time that underlies their overall holistic approach to the cosmos, where every microelement associates with meso- and macro-scale events and vice versa. In such a cosmology, individuals merely receive meaning as being part of a whole because the idea of eternally recurring cycles annihilates any form of individuality, creativity or newness, and in many ways, it therefore annihilates any sense of history. Instead, each hour, day, month, season or year finds its meaning only in being part of the eternally returning complete year, and every instantiation thereof in the form of relative time is merely a reenactment or reincarnation of the first cycle that becomes repetitively commemorated and reincarnated in festivities and ceremonies, each time anew. However absolute and true time might be, on a meta-level this leads to the annihilation of time because it is eternally repetitive.

Judeo-Christian tradition retains many elements that correlate with these sexagesimal cosmologies. We give three examples: the adoption of returning ceremonies, the use of numerological secret languages, and the production of almanacs. As Eliade (1954: 130) details, just as the Babylonians would repetitively commemorate the heroic acts of Marduk, so: "...the Christian liturgical year is based upon a periodic and real repetition of the Nativity, Passion, death, and Resurrection of Jesus, with all that this mystical drama implies for a Christian; that is, a personal and cosmic regeneration through reactualization in concerto of the birth, death, and resurrection of the Savior." Equally, the 12 days between Christmas and epiphany or Three-Kings-Day are a pre-configuration of the 12 months of the year to come, and each day has long been considered predictive of the weather for each coming month (Eliade 1954: 65). Even the death of Jesus, which for Christians marks the taking away of the sin (eating from the apple of the tree of knowledge), provides a fresh start each Spring anew with Easter. 
The Hebrew and the early Christians also practiced several kinds of numerology, where letters that make up words or names are added numerical values and the sum of the numbers of a word are correlated to specific events in time, they are presumed to have predictive power, or they get a positive/negative or sacred/profane connotation. The practice associates with sexagesimal number systems, where numbers receive their meaning by how they fit into or enable to calculate larger numbers, and traditionally, the numbers 6 or 60 have a prominent role. Christians for their part would actively counter the number 6 , and, as such battle the older numerological values. For Jewish scholars, the number 6 still has a positive connotation because of the 6 days of creation, but for the Christians, the number 6 , or a series thereof, such as 666 or 616 correlate with all bad things, including the devil or the anti-Christ (i.e. the number of the "Beast" as described in the Bible, Revelation 13: 1-18, which moreover can be interpreted as a reference to an older zodiac, apparently one based upon 10 signs). Numerology furthermore consorts with studies of geometry, the search for the Adamic or divine language (see Gontier 2009); and magic that provided the foundations for early alchemy where, in secret societies, scholars tried to transform the elements whilst reciting magical spells such as Abracadabra which literally translates to "I create as I speak" and thus with attempts at becoming as god. Numerology was extremely fashionable in the first 5 centuries and performed by Gnostics who were either covert "crypto"-Jews or sectarian Christians (De Libera 1995), and both were often prosecuted by the church as heathens for their creative interpretations of the scriptures. But from the tenth century onward, scholars such as Thomas of Aquinas, Raymond Lull, and Dante Alighieri would freely synthesize element thinking with Christian thought.

The politicization of the church and the Christianization of Europe opened the way for practices where not only the life of Jesus Christ became commemorated, but numerous local heroes would be turned into "saints". This can be understood as attempts to convert the "heathens" of Celtic, Gallo-Roman and Germanic descent, and such cyclic idolatry would eventually lead to internal disputes that were one of the factors for the reformation movements of the sixteenth century.

To tell which day correlates with which saint's commemoration, the Christians would adopt the practice of producing almanacs. Almanacs are not a Christian invention, it also has sexagesimal roots and it is associated with numerology (which probably derived from it), ceremonial repetitiveness and the zodiac-based study of the tempo and temperament. As Ptolemy had shown, the zodiac enables knowledge of the weather and knowledge on horoscopes that lend insight into the general Age-related zeitgeist as well as personality traits of individuals or cities. Ptolemy used a sexagesimal number system, but rather than finding meaning in the numerical cycles themselves, he was primarily interested in synthesizing sexagesimal timekeeping with Aristotelian causality, a practice that was followed by the Christians who had insufficient or no knowledge of the sexagesimal-based cosmologies.

The practice of producing almanacs is very old. From 2.000 BC onward, the ancient Hindu, Babylonians, and Egyptians, started to produce them on a yearly basis, and with the Greeks and especially the Romans, calendars would become widespread, not only amongst scholars, but amongst all citizens of the empire (Porceddu et al. 2008; Livingstone 2012). These almanacs provided the days and months of the year and the signs to which they correspond. They listed the beginning of the seasons, predicted sunsets and sunrises, the moon cycles, estimated eclipses, and they provided information on harvest and sowing times of crops as well as the dates of specific festivities and ceremonies. And based upon the importance that was given to the numbers or the commemorations, distinctions were made between lucky and unlucky days (hemerology), or periods in the month (menology). A yearly almanac thus provided an aid to farming and it suggested the rules of behavioral conduct. Today, we associate such horoscopes with superstition, but for the ancients and the scholars of the middle ages, these were predictive tools. The rules for prediction were formulated by Ptolemy whose work became translated in Arab in the eighth century and in Latin in the twelth.

2. Over the years, Christian almanacs would add and delete events, and the acknowledgement that historical events change over time again strengthened the idea that time and causality do not form a returning cycle of the same and similar, but a linear and sequential series of unique events, a sequence that can be captured chronometrically by dividing time into a past, present and future. Such chronometrics founded historical research which for the scholars of the Middle Ages mainly encompasses a chronological investigation, and chronologies became depicted in uni-linear timelines.

Yearly almanacs would come to serve as historical documents wherefrom Christian chronicles were written. Chronicles are semi-religious, semi-historical works on the act of creation and the subsequent history of humans, from Adam and Eve onward. One such example is the Book of Chronicles, today known as the Nuremberg Chronicle, published in 1493 in both Latin and German, and written by Hartmann Schedel. Amongst other things, this "world history" book describes the origin of the major European cities and gives the non-evolutionary genealogical pedigrees and thus trees of their major leaders. The chronicle furthermore opens with a detailed multi-illustrated description of the Judeo-Christian religion's 6 days of 
creation. The final illustration of these creation days (Fig. 3) provides a good cosmographic summary of the cosmology endorsed by the Christian scholars.

The illustration depicts a series of circles around the geocentric and thus Ptolemaic earth that appears to be drawn upside down. Following Plato and Aristotle's lineup of the elements, earth is surrounded by water, air and fire (the atmosphere). After the elements, the presumed perfect circular orbits of celestial bodies are depicted (the Moon, Mercury, Venus, the Sun, Mars, Jupiter, Saturn), followed by the tropical zodiac. With the zodiac, we reach the hypothesized firmament: the division between the physical and metaphysical or transcendental, which is assumed to be separated from one another by a crystal ceiling. Above the crystal ceiling we find Aristotle's prime mover, the first causal principle that sets everything in motion. And above the prime mover, we find the Christian god in heaven surrounded by angels, saints and other supernatural beings.
Following Aristotle, the Christian god is argued to have neither cause nor movement, and following Plato, he is eternal or, stated otherwise, he is the only one above space and time.

In the corners, and in a clockwise direction, we find the four cardinals (Subsolanus or East, Auster or South, Zephyrus or West, and Aparctias or North) that, when viewed upside down, somewhat align with older cosmographies. Besides the zodiac, that places Aries completely out of sync to the right, and the planets, they mark the only remnants of ancient timekeeping of which knowledge appears to have been refuted, lost or unknown to the illustrator.

While ancients believed that the complete cycle recommenced each Great Year anew, according to JudeoChristian religion, matter, space and time are created by a deity only once and in but 6 days. What we see in the illustration is day 7 , where the Christian god supposedly rested and looked down upon his creation.
Fig. 3 Cosmography of the Nuremberg Chronicle (Schedel 1493) that combines ancient Greek wisdom with the JudeoChristian writings. Obtained from Google Books that is under a Creative Commons License at https://books.google. pt/books/content?id= IeUOAQAAMAAJ\&hl=nl\&pg= PT15\&img=1\&zoom=3\&sig= ACfU3U1Wph zOinFWQNMICjlvDgOMWKXw\&ci $=152 \% 2 \mathrm{C} 371 \%$ 2C765\%2C923\&edge $=0$

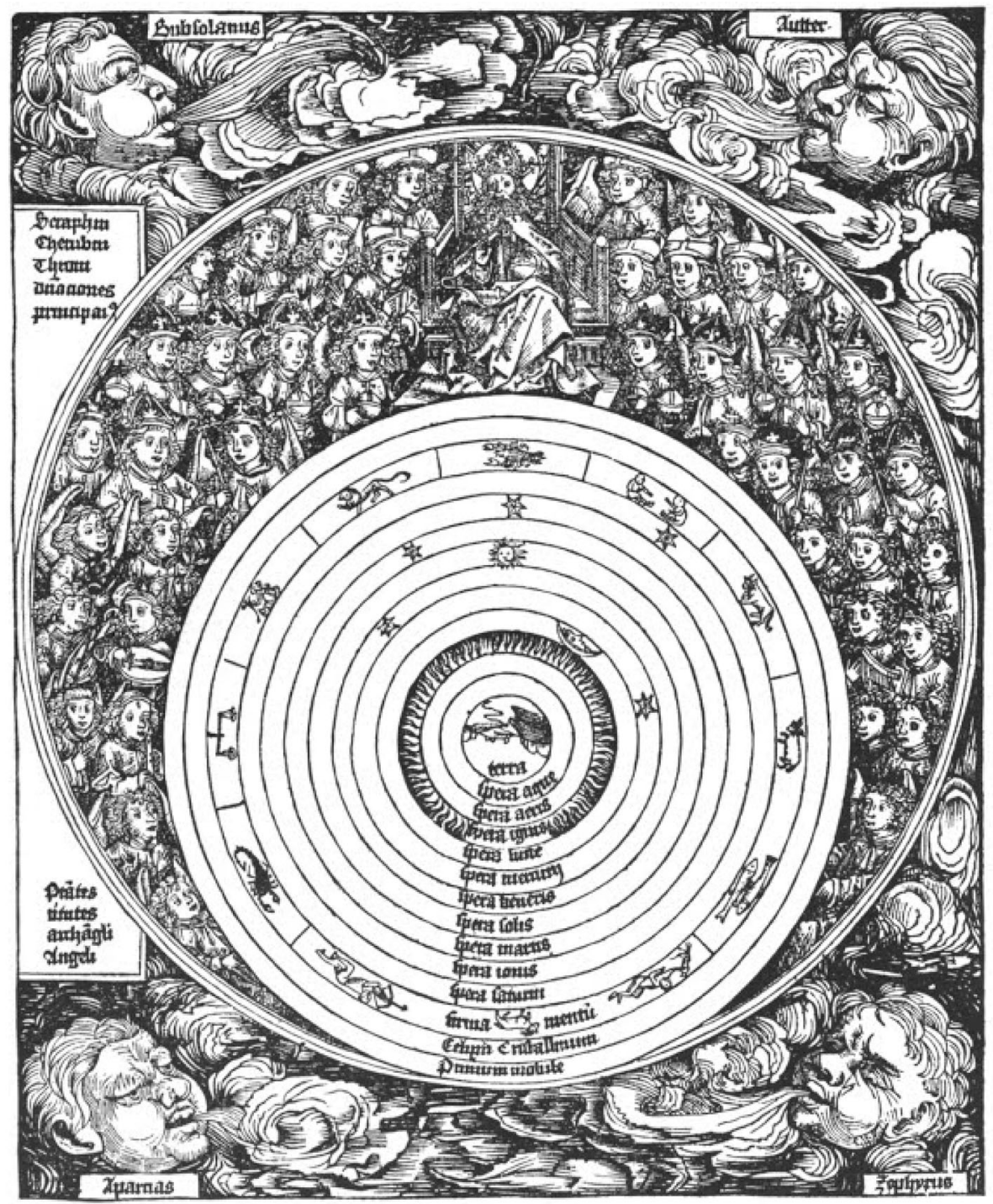


So what happened after day 7 ? Instead of cyclically recommencing, day 7 was followed by day 8 , that was followed by day 9 , and the days would line up to form a year, that was followed by another, and so on. After explaining the creation days, Schedel therefore goes on to give a chronological timeframe that is based upon calendar years that he distinguished into 6 different historical Ages of the world (from the Greek Aeon). These go from Adam to the flood, 1.656 years; to the birth of Abraham, 292 years; to the beginning of the Kingdom of David, 940 years; to the Babylonian captivity, 485 years; to the destruction of the Temple of Jerusalem and the birth of Jesus Christ, 590 years; to the end of the World, which only God knows. Macro-Ages were thus calculated upon a literal interpretation of the Biblical texts, and therefore became interpreted independently of the ancients' uniform estimations of the Ages of the Zodiac (2.160 years) and the return of the Complete Year (25.920 years).

Schedel's different estimations add up to 3.963 years, and when we add to that the numerical time from year 1 onward (the hypothesized birth of Jesus), which for Schedel corresponds to 1.493 , i.e. the year wherein he published his chronicle, the world is estimated to be 5.456 years old. Here lie the roots of what we today call "young earth creationism" that, given the passing of numerical time since the Middle Ages, and with some minor recalculations, currently assumes the earth to be around 6.000 years old. Note that the lifespans of the different ages of numerical time have no uniformity. The years, however, are calculated as Julian calendar years and these do have regularity: 365 days per year that are intermitted with a 366th day every 4 years. The reason for the jumpy historical chronology is that in their theistic worldview, historical events do not need to follow regular laws, they are expressions of divine will.

Nonetheless, in true accordance with more ancient sexagesimal-based cosmologies, where every hour or day repeats, represents and perhaps even embodies a part of a greater cycle, Schedel noted that the 6th age can be considered "the last hour", which he predicted could end any day soon with the promised apocalypse. In line with the preaching of the Church, he added a 7th age that runs parallel with the 6th that contains all the peoples at rest (the dead), of which he predicted that their souls would resurrect in the 8th age, the moment when all return to paradise for all eternity. This therefore corresponds with the end of historical time.

Continuing both the macro-, meso- and micro-divide of ancient cosmologies and horoscope formulations on the temperaments, and in true ancient style, Schedel also divided human life into another 6 (st)ages, going from infancy, from birth to the age of 7; over childhood, to 14; to maturity, 38; and youth, 49; to timely, 79; and spent, from
80 until death. This makes $7,15,39,50$, and 80 special numbers. These stages mimic the Ages and again follow no regularity or uniformity other than the length of the years that follow the calendrical time. So while practices and ideas continued to associate with those of older cosmologies, much of their original meaning was lost and new interpretations, in sync with the Judeo-Christian genesis and apocalypse stories, were given. Afterwards, Schedel lists the formation of the major European cities and gives the non-evolutionary genealogical pedigrees of their founders.

Circular illustrations such as Schedel's cosmography would on the one hand come into disuse due to the rise of the heliocentric worldview; and on the other hand, chains of being would continue to expand and include more and more elements in association with the rise of the periodic table. Such chains of being would become linearized into scala naturae that, on a meso-level, included more and more genera and species. The term derives from a passage in Aristotle's work where he mentioned the idea of a "scale of ascent". For Aristotle, this related to his idea of all life forming a chain that was subjected to an eternal cycle of coming and becoming, but for the Christians, scales became stairways to heaven. Following Plato's Allegory of the Cave and Aristotle's three soul theory, scala naturae order the elements and creatures based upon their level of perfection, a perfection that is measured by the kind of soul creatures have (a vegetative, animalistic or intellectual one), which defines how close they find themselves to the Christian deity. Man, having been created in his image and sharing his ability to think and speak was considered to be the summon of creation, only to be outcompeted by supernatural beings such as saints, angels and God.

What is interesting in this regard is that early historians were preoccupied with reconstructing the chronology of the historical time of man, and such chronologies were numbered since the days of creation onward, but the scales that depict genera and species would remain void of any such numerical calculations. With the rise of chronologies such as the one written by Schedel, only the history of man since creation would become numbered, and these days were numbered because of the predicted apocalypse. Scholars simply did not assume that genera and species also underwent changes in history. Instead, and in line with their Genesis story, all living creatures were considered to have been created in their fixed state by God during the early days, and named by Adam. At most, they were considered innocent and void of sin, and their history therefore remained unchanged.

In sum, the cosmology that most influences our linear notion of time is the Judeo-Christian one, where both time and causality become understood not as chain but as a linear and sequential series of historical events, a sequence 
that can be captured chronometrically by dividing time into a past, present and future, and one that can be calculated by calendrical years. Every event becomes historically unique, but what happened in the past (the sin) has a consequence on the present (the fall) and the future (the return to paradise). Events come to predict a chronological teleology, because their deity has determined all events that have and will take place, from creation to the apocalypse. This leads to a teleological determinism, because the future is to some extend predictable because humans have received knowledge of the sequence of events that have and will occur, through their respective spokesmen, in the form of both language and mathematics. In their theistic worldviews, the deity can intervene at any moment in creation, at will, and no regularity therefore can or has to be found in the way by which historical events take shape. That is why the lifespan of the different ages can be jumpy or what naturalists would come to call catastrophic. However, the "steadiness" of a year was simply taken for granted. Such chronometrics in turn underlie the introduction of historical research which for the scholars of the Middle Ages mainly encompasses a chronological investigation into the sequence of events over numerical time, and chronologies became depicted into linear timelines.

\section{Natural History: The Consequences of the Decimal Number System}

The conceptualization of time as a single and uni-linear sequence of historical events is by and large determined by Judeo-Christian cosmology. This unilineal scale can be conceptualized both as jumpy, which is the case with the different ages since creation (historical time), and uniform, because eventually, the jumps in historical time are measured over uniform years that are calculated in accordance with the Julian calendar (true, yearly time).

In what regards yearly time, physicists and astronomers would continue to understand it as resulting from the study of planetary motion, and they would come to understand the perfect harmony they presumed in celestial motion to be an expression of God's omnipotence that they readily portrayed in their cosmographies. While chronicles such as the one written by Schedel started to number the days of human history, none of the circles or scales would include a numerical timeframe based upon calendar years. The reason is that Christians assumed both celestial motion and the scale of nature to be fixed and created in its present form. Here we first describe how the shift from a geocentric to a heliocentric worldview, the introduction of the pendulum clock, and new notions of automata underlies transitions into matter, space and time thinking and we investigate how they underlie mechanical and uniform causality thinking. Secondly, we investigate how the transitions in physics and causality thinking impact the rise of natural history and when and where in the scales of nature, numbers do become added.

1. The problem of getting the numbers of yearly time right and keeping them in line with the seasons (crucial for agriculture) and associated festivities (necessary for the church to maintain credibility as a political institution) remained problematic. New astronomical measurements and calculations were therefore often made at the request of the church, which eventually led to the reform of the Julian to the Gregorian calendar in 1582. The reform mostly involved a recalculation of Easter (the resurrection of Jesus) that used to coincide with the first full moon after the Spring equinox (the Hebrew Passover: the liberation from Egyptian slavery by Moses).

Such recalculations would start to question the Greeks' geocentric worldview, a worldview that the church had adopted in their teachings. Basing his views upon old Iranian manuscripts, Copernicus (1473-1543) was the first scholar of the Middle Ages to suggest that the earth is a sphere that rotates around its own axis, and that our globe in turn revolves around the sun, resulting in the sun (or a point close to it) and not the earth being the center of the universe. His theory can be summarized by the 7 postulates he formulated in an unpublished work that he distributed amongst his colleagues (Table 4). He divulgated the work before he wrote his magnum opus, On the Revolutions of the Celestial Spheres (De revolutionibus orbium coelestium) that was published posthumously in 1543 (Copernicus 1939), in the very same city of Nuremberg where Schedel had written his Book of Chronicles about a hundred years earlier.

Copernicus dedicated his work to Pope Paul III, because the church had asked him to refine the equinoxes, and this research made him obtain knowledge of the earth's precession and its associated phenomena. The pole star, the equinoxes and the zodiac appear to shift over time, but Copernicus says they are fixed. It is the earth's rotation around its own axis and the earth's rotation around the sun that appears to make "the firmament and highest heaven" rotate while, for Copernicus, they do not undergo any motion. He distinguished between three earthly motions: an annual rotation around the sun in the order of the signs of the zodiac, the daily rotation of the earth around its own axis, and the earth's wobble around its own axis, which he called the motion of declination (calculated at $23.5^{\circ}$ ). He was unable to provide a reason for the latter, but he compared the poles to magnetized iron needles that always point toward a single spot in the universe. He also believed that the sun itself did not revolve.

With his theory, Copernicus did not so much want to question the tenets of Christian religion, but the Greek 
Table 4 Copernicus' 7 postulates of his heliocentric worldview

"1. There is no one center of all the celestial circles or spheres

2. The center of the earth is the center of the universe, but only of gravity and of the lunar sphere

3. All the spheres revolve about the sun as their mid-point, and therefore the sun is the center of the universe

4. The ratio of the earth's distance from the sun to the height of the firmament is so much smaller than the ratio of the earth's radius to its distance from the sun that the distance from the earth to the sun is imperceptible in comparison with the height of the firmament

5. Whatever motion appears in the firmament arises not from any motion of the firmament, but from the earth's motion. The earth together with its circumjacent elements performs a complete rotation on its fixed poles in a daily motion, while the firmament and highest heaven abide unchanged

6. What appears to us as motions of the sun arise not from its motion but from the motion of the earth and our sphere, with which we revolve about the sun like any other planet. The earth has, then, more than one motion

7. The apparent retrograde and direct motion of the planets arises not from their motion but from the earth's. The motion of the earth alone, therefore, suffices to explain so many apparent inequalities in the heavens"

Fragment from Copernicus unpublished work, the Commentariolus (in Rosen 1971: 58-59)

ideas on uniformity on which they rested, for as he noted: "Our ancestors assumed, I observe, a large number of celestial spheres for this reason especially, to explain the apparent motion of the planets by the principle of regularity. For they thought it altogether absurd that a heavenly body, which is a perfect sphere, should not always move uniformly. They saw that by connecting and combining regular motions in various ways, they could make any body appear to move to any position." (Copernicus, Commentariolus, in Rosen 1971: 57)

The Greeks never assumed that all planets move at equal speed, but they assumed that there was regularity in the movement of celestial bodies, and geometric regularity in the shapes of the universe. This uniformity was found by assuming that all movement was circular and that all possible shapes are contained in a circle. $360^{\circ}$ geometry enabled them to understand a day as something that takes 2 times $12 \mathrm{~h}$, and a year as the sun's regular movement through the 12 signs of the zodiac. Copernicus (Commentariolus, in Rosen 1971: 59), however, after demonstrating that earth has 3 different movements, hastened to say that: "Having set forth these assumptions, I shall endeavor briefly to show how uniformity of the motions can be saved in a systematic way."

It takes 186 days, for example, to go from the vernal to the autumnal equinox, but 179 days to go from autumn to spring. This implies that neither Earth, nor its orbit around the sun, is perfect and uniform, and what is at stake is thus the question of how uniform motion of matter in space and time really is. With Earth and all other planets revolving around the sun, and as Kepler would demonstrate, in an elliptic way, it brought forth a question of uniformity and speed and how to measure it (by the equinoxes, the fixed stars, mass or its weight, or later heat, light or radioactive decay).
Nothing of this necessarily has to do with timekeeping (although it can), but with the study of motion of matter; how uniform that is and against which (numerical) frame of reference we calculate it. That is why Galileo Galilei (1564-1642), after proving the earth's rotation by examining the ebb and flow of the sea, took on the above question and introduced the two new sciences of matter in motion: material science and kinematics in his Discourses and Mathematical Demonstrations Relating to Two New Sciences (Discorsi e Dimostrazioni Matematiche Intorno a Due Nuove Scienze). Galilei (1974) defined uniform motion as motion that over an equal period of time covers an equal distance.

Johannes Kepler (1571-1630), a student of Tycho Brahe and contemporary of Galilei, introduced the laws of planetary motion around the sun and demonstrated that planets not only orbit in ellipses instead of perfect circular motions, but at different speeds. This did not make him think that the universe was any less perfect though. Kepler in his The Mystery of the Shape or Cosmography of the Cosmos (Mysterium Cosmographicum, 1596) still held immense fascination for Plato's solids and how they define the perfect geometric shape of the universe, the planets and their motions (Dreyer 1953) and he went on to develop his own solids (today known as the Kepler solids). He even presented himself as a new spokesman, stating that he received his ideas during an epiphany which inspired him to demonstrate how beautiful and complex the Christian deity had made the universe.

Descartes (1596-1650) however was less optimistic. The advances his contemporaries, Galilei and Kepler, had made in physics, made him create doubt about the truth value of ancient knowledge. Instead, he sought refuge in rationalism, and argued that man is entirely capable of thinking space and time by using his intellect. And with the 
introduction of his two-dimensional coordinate system, he would straighten the circle out once and for all.

Descartes had set forth to solve the mysteries of physics, all by himself, in a work titled Essay on the world and light (Traité du monde et de la lumière). He never published the work because, on the one hand, the condemnation of Galileo's work made him cautious, and on the other hand, as he explains in part 6 of his Discourse on the method to rightly steer one's reason, by searching for the truth in the sciences (Discours de la méthode pour bien conduire sa raison, et chercher la vérité dans les sciences), he came to realize his naiveté, because to prove his ideas, numerous experiments would have to be conducted for which he had neither the lifetime nor the money.

In the work, Descartes later elaborated (1998, Discourse, part 5), he attempted to explain how the universe could have formed gradually out of a material chaos, by natural laws, and reasoned that " ... if we think of material things as developing gradually out of chaos, their nature is easier to grasp than if we considered them only in their present completed form. And there is nothing wrong with believing that God could have brought them about in that manner, starting with chaos, establishing the laws of nature, and then allowing nature to develop in a normal way in accordance with those laws."

Descartes was thus opposing theism that assumes that the Christian God created the universe in its fixed form and that he intervenes in creation (matter, space and time) at will. Instead, he introduced a deist position, the Christian god had created the universe and the natural laws, but once created, neither the cosmos nor the laws of physics require divine intervention because they work perfectly mechanical, as machines. Descartes reasoned by analogy, that just as a body can function perfectly by its organic parts and by the circulation of the blood, so the natural world can function perfectly according to natural laws. Human reason was an addition, provided by God, and by analogy of his mind/body divide, God did not have to intervene in his creation (the solid body that the universe was) but could remain outside of it. Instead of having been created wholesomely, he assumed that the natural world could have developed gradually out of material chaos, from simple to more complex forms, and in that regard, he was greatly fascinated by transmutations such as the formation of glass from the ashes of fire.

Descartes (1998, Principles II, 10-16) materialized place and space by understanding the cosmos as a material plenum which means that there is no void or vacuum (space), only matter ("the extension in length, breadth and depth that constitutes a space is exactly the same as the extension that constitutes a body", and he of course subscribed to the existence of ether as being part of matter).

In so far as matter exists, it has duration. Duration he defined as the movement of matter (though he assumed that matter can also be at rest in which case it continues to have duration) and for particular movements of particular objects, he pointed out that we make use of the decimal number system, while for the duration of all things (the sum of these movements), we compare them to celestial motion and we call it time (based upon years).

\begin{abstract}
"Now some attributes or modes are in the very things of which they are said to be attributes or modes, while others are only in our thought (in nostra tantum cogitatione). For example, when time (tempus) is distinguished from duration taken in the general sense (duratione generaliter) and called the number of movement (numerum motus), it is simply a mode of thought (modus cogitandi). For the duration which we find to be involved in movement is certainly no different from the duration involved in things which do not move. This is clear from the fact that if there are two bodies moving for one hour, one slowly and the other quickly, we do not reckon the time to be greater in the latter case than in the former, even though the amount of movement may be much greater. But in order to measure the duration of all things (omnium durationem), we compare their duration with the greatest and most regular motions, which give rise to years and days, and call this duration 'time' (hancque durationem tempus vocamus). Yet nothing is thereby added to duration, taken in its general sense, except a mode of thought." (Descartes 1998, Principles I: 57)
\end{abstract}

This definition of relative/numerical and true time based upon years is very close to Plato's, who defined true time (the complete year) as the sum of all motions when they come to a head, and this time was a model shaped by the Demiurge in the image of eternity. Scholars debate whether this was a realist or idealist position, but Descartes leaves no doubt: we add nothing by stating things like this but a mode of thought, a mental concept or idea. Both numerical time derived from number (duration) or time derived from the motion of celestial bodies are therefore "mere" properties or mental attributes we give to matter, and space too is merely an attribute of the mind.

In one of the appendixes of his Discourse, De La Géométrie (On Geometry), Descartes went on to suggest that we track how matter moves from within a two-dimensional coordinate system (Fig. 4). Merely analyzing the system from a visual point of view, we find that point zero, called the origin, marks the middle between unreal, regressing and real, progressing numbers. If we let $\mathrm{x}$ stand for time and $y$ for space (or vice versa), then what is formed in quadrant $\mathrm{I}$, the quadrant of the real numbers, is the material plenum, and any movement of his corpuscular matter can be tracked along the coordinating axes from point zero onward. Such tracking enables the measurement of 


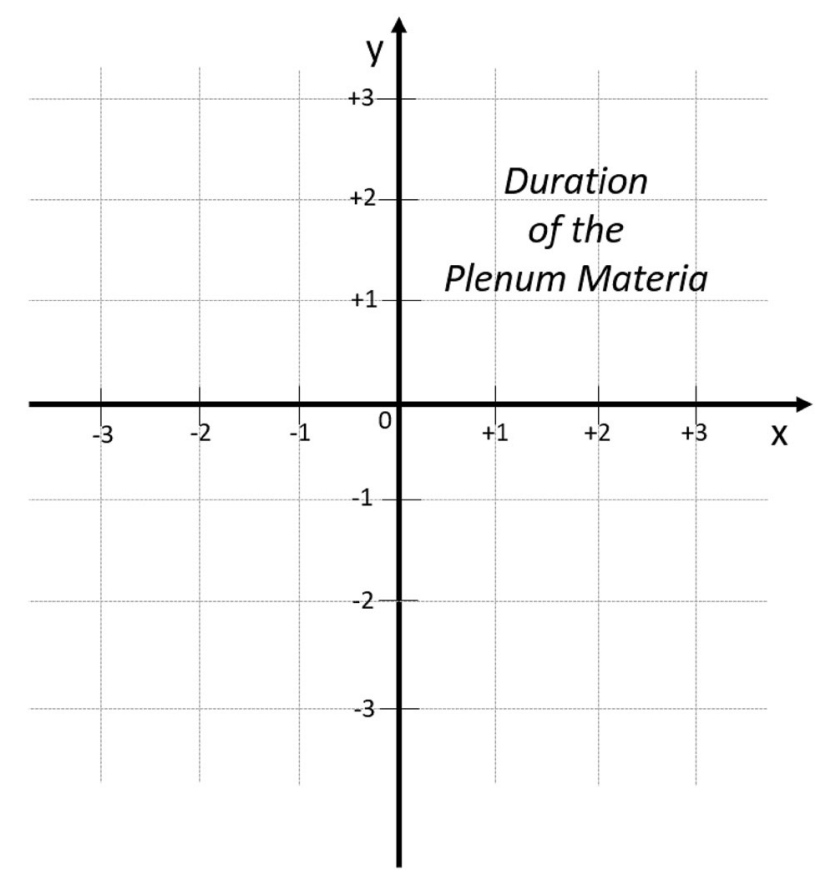

Fig. 4 A Cartesian coordinate system

duration, the matter that is in motion. Consequently, any movement of matter in the Materia Plenum can only go rectilinearly upward or forward.

Both space and time, for Descartes, as well as numbers (see e.g. Principles, I, 57-58) are mental concepts that we attribute to the matter in motion, to enable us to coordinate and measure it, and just like the unreal numbers, also the $\mathrm{x}$ and $y$ axes stand outside the material plenum. The other quadrants are unreal. When we compare or interpret these from within older cosmologies, the other quadrants can be understood as "chaos", the "underworld", "the dead", or "God" that all stand outside the real system (i.e. the physical world of matter that "occupies" "space" and "time", or what we would call spatio-temporal existence). From a historical point of view, quadrant I from point zero onward marks the beginning of history (the birth of the city of Rome, the birth of Jesus, or the birth of the cosmos in a big bang theory), and everything before point zero becomes either "pre"-historic, "pre"-cosmic, or unreal.

In other words, Descartes' coordinate system describes the plane by two coordinates, $\mathrm{x}$ and $\mathrm{y}$, and has as main purpose to understand the non-coordinate, axiomatic Euclidean geometry (shapes or as Euclid's work on geometry was called: the elements) from within the algebraic system (numbers). The $\mathrm{x}$ and $\mathrm{y}$ axis thereby become straight number-lines set apart from one another at a uniform distance. In such a system, we can track how A goes to $\mathrm{B}$, and we can backtrack the motion, by investigating how $\mathrm{B}$ comes from $\mathrm{A}$, and that is exactly what his scientific method implies.
Radically opposing his views to Aristotle, he rejects the formal and final cause that asks about the essence and final goal of a thing, i.e. their inner wantings or inner movements, and argues that science can only answer the howquestion that asks about the external or efficient cause of movement. Only how and from what A goes to B becomes relevant; Descartes (1998, part 6):

For it seems to me that reasons are interlaced in such a way that just as the last are proved by the first, which are their causes, so the first are proved by the last, which are their effects. Don't think that I am here committing the fallacy that logicians call 'arguing in a circle'; for experience makes most of these effects quite certain, so that the causes from which I deduce them serve not so much to prove them as to explain them-indeed, on the contrary, it is the effects that prove the causes.

We can either follow causes to their effects, or effects to their causes, which answers the mechanical question of how matter moves by external force. But here is where he got stuck in providing his all-encompassing theory of physics. To demonstrate the sequence going from A to B or vice versa, one needs to conduct experiments that provide proof for which he neither had enough time nor money. In any case, for Descartes, all external motion can be explained by plotting how A causes B, and in the absence of external force, there is no internal wanting, but objects will move uniformly in a straight line (what we today know as Newton's first law). From within his deductionist approach, Descartes (1998, Principles II 37-39) thus continued to make several assumptions which he formulated in terms of his 3 laws of motion.

Descartes laid the foundation for a purely physicalist view, where the study of matter, space and time becomes reduced to the study of matter in motion, and physical laws become quantifiable. He also laid the foundation for mechanical thought, by focusing on how a whole is determined by the functions of its parts. As such, he did not deny that bodies can have an internal movement, in fact, bodies can become decomposed into their organs, and their mechanical functioning explains how and from what a body becomes like a machine. Both views imply a reductionist stance because a whole is the sum of its parts. And with such stance, space is merely the sum of all matter, and time is merely the sum of all duration (of matter in motion) set against celestial motion. Consequently, the study of causality becomes defined as the study of how A, the cause, leads to $\mathrm{B}$, the effect, and the (assumed) linear sequence of events going from $\mathrm{A}$ to $\mathrm{B}$ provides the causal explanation. $\mathrm{B}$ minus A provides the duration which is expressed by a linear decimal number line. 
As scientific as it all sounds, Descartes continued to invoke the existence of the Christian God and used it to prove the certainty of his thoughts. While duration of all matter in motion defines all being or all existence, his cogito ergo sum (I think, therefore I am) places reason above the realm of being and gives priority to it. This can only be explained from within his ideas that both being and thinking are of divine origin, and that humans share these properties with their god, making them become as god. And this in turn expresses the typical zeitgeist of modernity: man is glorified as a rational being entirely capable of knowing all the mysteries the world entails, he can make inferences about the past, and he can even predict the future. Scientifically speaking, he can distinguish truth from falsehood, and morally speaking, he knows right from wrong. As such, he can even turn the world into a better place.

Newton would put it all together and found the field of classical physics. He agreed with Descartes that when we use terms such as time, space, place and motion, we refer to quantities of objects that enable measurement, and more inspired by empiricism, he understood these quantities as mere inferences we make from our sense perceptions onto those objects. Nonetheless, he distinguishes these notions from an absolute space and an absolute time (Schliesser 2013). He defined absolute time as duration understood as a "uniform flow of time" by itself, according to number, without reference to any external objects. Relative time is any external measurement of this duration, by, for example, the study of the motion of objects or celestial bodies from which we derive tempo. Newton in Schliesser (2013: 90):

Absolute, true, and mathematical time, in and of itself and of its own nature, without reference to anything external, flows uniformly and by another name is called duration. Relative, apparent, and common time is any sensible and external measurement (exact or nonuniform) of duration by means of motion; such a measure-for example, and hour, a day, a month, a year- commonly used instead of true time.

Note that the year, month, day or hour merely become an example by which we can measure true time, while true time is absolute and mathematical because it is defined by number. While Plato and Descartes understood any notion, idealist or realist, of true time as based upon celestial motion (for simplicity, let's call it calendrical), Newton equates true time with the decimal numerical system, and the Greek and Latin tempo merely becomes one measure amongst many.

He reasons as follows. Different celestial bodies and different day to day objects move at different speeds, so there might not be a uniform motion by which we can measure these tempos (not as weather but as speed). But such is not the case (for that reason he would introduce his universal law of gravitation, but here we focus on his ideas on time). "All motions can be accelerated and retarded, but the flow of absolute time cannot be changed. The duration or perseverance of the existence of things is the same, whether their motions are rapid or slow or null; accordingly, duration is rightly distinguished from its sensible measures and is gathered from them by means of astronomical equation." (Newton in Schliesser 2013: 91)

In other words, and placed more in a day to day context, Newton distinguished between time understood as the study of motion of objects, and absolute time. The former is always relative, because a turtle or a jaguar, for example, move at different speeds. But this does not take away from the fact that both move according to number, where each number uniformly follows the other; the numbers themselves do not change. Just as the speed by which a turtle or a jaguar moves has no impact on their entire lifespan, and though their speeds and directions in which they move can be accelerated or slowed down, absolute time is not impacted by the different relative times there are. Absolute time, though "gathered by astronomical equation", is subordinated to mathematical number. For that reason, absolute time is irreversible. Even if we were to backtrack all the steps we have taken since yesterday, we would not be going back in time, we would merely turn around the motions we did the day before in a later period in time.

As such, absolute time as duration gives an inevitable rectilinear directionality, one that became understood as going from the simple small numbers to the complex bigger ones, and one that therefore progresses, along a given and rigid number system that undergoes no change. Herein lies the foundation for what I call mechanical teleology in Table 1 . In an absolute space and time, and with perfect uniform mechanical laws, the future is predictable, and the past can be inferred.

It is somewhat ironic that the Greek true time, which for them coincided with the Complete Year that was researchable by number, now becomes subjected to that very same number, the rectilinear decimal number system as plotted in a Cartesian coordinate system (or for that matter a multidimensional vector space when we add more dimensions). It is the number system that provides uniformity and homogeneity to anything we call time. It is also here that Newton deviates from Descartes, who associated omnium durationem or the duration of all things with timekeeping which he considers the most uniform one, while duratione generaliter refers to the number of a particular movement (numerum motus) calculated by number by the intellect.

Schliesser (2013: 97) points out that with Newton "all moments in time have identical fixed relations" and as such, Newton overrules the idea that a deity can make and 
bend time at its will, or even "move temporal places around", thereby making time or space irregular because he assumed that "just as the order of parts of time is unchangeable, so, too, is the order of the parts of space". The latter founded Newton's notion of an absolute space. It is also a deistic move, but while Descartes placed the Christian deity outside the material plenum, for Newton, the Christian deity, though he does not coincide with duration and space, nonetheless endures and is present, in all possible worlds, because in his assumed omnipotence, the Christian deity cannot be never/nothing and nowhere. This can even be understood as a pantheistic move, one also made by Spinoza in his criticisms of Descartes, where God is considered to be part of everything, all the time and everywhere.

In sum, with Descartes and Newton and the rise of classical physics, numbers become equal in the sense that they are merely defined by their position in a linear lineup, and especially the Cartesian two-dimensional coordinate system visualizes how they are set apart at an equal distance. It is important to note that this linear mathematical order gives a different sense of directionality than a sexagesimal number system, where numbers obtain their meaning by the way in which they represent and enable to calculate the cycle, and it differs from the non-uniform Judeo-Christian notion of historical time that is ruled over by divine will. Linear mathematics itself determines the sequence and this also gives a different notion of causality: 2 logically follows 1 , and 3 cannot precede 2 . In a linear sequence of events, A causes an effect or outcome B, but the outcome $\mathrm{B}$ cannot cause $\mathrm{A}$, and the reason given is that $\mathrm{A}$, the cause, has antecedence and precedence over $\mathrm{B}$, the effect, that has contiguity. In other words, A precedes B in both time and space. This causal sequence of events is thus formulated in a spatial and timely fashion. 1 comes before or earlier than 2 and 3 comes after or later. Such gives a sense of linear time, a time that is no longer cyclical, but one that becomes divided into a past, present and future.

2. How then does all of this influence the rise of natural history research? Well, it would have been interesting if the natural history students would have entered the scene where the physicists had left it, but such is not the case. Instead, they went through similar developments, and their works became an interesting mix between ancient Greek endeavors to find the scales and cycles that run through natural history, and Judeo-Christian endeavors to time history since creation, by way of establishing chronologies.

These chronologies were originally based upon textual interpretations of the Bible, and measured against calendrical time. As such, Christian calendrical time functioned as a constant frame of reference. In his Opus novum de emendatione temporum (New work on the amendment of time) Joseph Justus Scaliger (1583), and drawing upon
Copernicus' work, provided a new method that enabled him to convert the various ancient calendars of the Persians, Babylonians, and the ancient Greeks (sexagesimal and decimal-based) to the Julian calendar. This facilitated not only integration but also comparison of the different time periods of ancient chronicles and calendars with the Christian one, and it facilitated the conversion of chronicles into numerical chronologies. The work would much later be revised by Newton (1728), in his essay on The Chronology of Ancient Kingdoms Amended.

Coming to terms with the fact that the history of western man changes over time, and that it differs from the history of other cultures and ethnicities, what early natural history students, understood as moral philosophers, historical linguists, ethnologists, and historians (of science) focused on, was finding the principles or laws that govern these historical changes. Such principles would be defined by seriations or stages of history much more so than that they were based upon number. The Julian and Gregorian calendar as well as timeframes provided in chronicles such as the ones introduced by Schedel and Scalinger were simply taken for granted.

Moral philosophers such as Adam Smith, Thomas Hobbes, David Hume, and Jean Jacques Rousseau, for example, as well as early historical linguistics and ethnologists, would investigate the natural history of languages and cultures, and they intertwined these ideas with moral and political thought on how to organize society (for an overview, see Gontier 2009). In association, they would provide speculative seriations of how man developed from a "primitive lawless state" to "civilized industrial and rational men". Today, we know such seriations that associate with the introduction of the nature/culture divide as developmental stage thinking or historicism (for a critique, see Popper 1957).

The term "evolution" comes from the Latin evolvere, which means development or to unroll a script. In this meaning it was used by preformationists to explain the development of the individual from sperm or egg onward as the unrolling of a divine script. But the term "development" would also be used by the early natural history students, to explain how man developed from a state of nature, often understood as a paradise lost in line with Biblical creation stories, to a state of culture.

Adam Smith (1723-1790), for example, distinguished between 4 developmental stages going from hunter-gathering to pastoralism, agriculture, and commerce/ industrialism. Georges-Louis Leclerc, Comte de Buffon (1707-1788) and Johann Blumenbach (1752-1840) would develop racial theories wherein they attempted to seriate the different ethnicities, and these theories would assume principles of "progress" and "degeneration" to explain variation. And August Comte (Martineau 1865), one of the 
founders of sociology, and also before the introduction of evolutionary thought, characterized the natural history of Europe as having developed over three stages going from the theological stage (characterized first by fetishism/totemism, then polytheism, and later monotheism), to the metaphysical stage, and ending with the positivist/scientific stage where rational thought prevailed.

In scales like these, one can move up or down the ladder, but that does not impact the flow or directionality of increasing complexity. When early natural history students and later social Darwinists argued that modernity runs from hunter-gatherers to farmers to industrialized men, they understood this sequence as law-like and given, and cultures with non-industrialized lifestyles became understood as having regressed to a more "primitive" state, or as being "stuck" in time and still in need of the "given" or "predictable" "development". Even before the introduction of evolutionary thought, scala naturae were turned into chronological seriations that did not so much provide a time frame but instead marked the underlying laws or patterns of historical change. In such views, one can ascent or descent the ladders, but the series itself is given.

Scala naturae were replaced by networks and trees and the ancient Greek micro- meso- macro-distinctions that underlie the older scala naturae also started to function as a division for the modern sciences. Physicists studied the universe on a macroscale. On a microscale, chemists examined how the elements relate to one another (by showing affinity), and how they can transform and transmutate; and biological, societal and earthly change was studied on a mesoscale. But what is most interesting is that many of these chronologies understood as seriations lack any reference to an actual timeframe.

Such is also the case for the early work on the earth's layers, performed by Nicholas Steno (1669: 214-215) for example, who argued that different strata result from different deposits that contain different fossils. His analysis provided the principles of superposition, original horizontality, lateral continuity and cross-cutting relationships but no real numerical timeframe. Instead, he investigated how natural solids are subjected to forces coming from their elements. All solid bodies, he argued, were once fluid, and their movement could be explained according to the Aristotelian wantings of their elements, as well as force induced by humans and the Christian deity.

Time only became a problem with the rise of later emerging geological research. Gould (1987) and as he noted in the introduction to his Time's arrow, Time's Cycle, by following Eliade (1954), demonstrated how early geologists such as Abraham Werner, Thomas Burnett and James Hutton went back to ancient Greek cosmologies from which they borrowed their cyclic notions of time. Simultaneously they made use of Judeo-Christian catastrophes such as the flood and prophecies on the inferno, and purgatory, especially as they were formulated by Dante (who in turn was highly inspired by Islam) to explain earth's strata. In true ancient style, they investigated how the elements, land (earth), sea (water), wind (air), and heat (fire) lie at the origin of the earth's layers. In their cosmogonies (which, like chronicles, are semi-religious works on the origin of the cosmos), they investigated how the elements impact the earth, how they materialize and erode, and how they bring forth the natural seriation of earth's stratigraphic layers as well as the fossilized species we find within them. While these seriations could be jumpy and bumpy, with the works of Lyell (1830, 1832, 1833), the endless cycles of deep time began to resemble clockworks and catastrophism became replaced with uniformitarianism that endorses a causal teleology, where the present presumably enables one to infer the past and to predict the future.

The geological strata follow a natural seriation, and this stratification, as well as the fossils found within them, first functioned as a record or natural chronology that was based more upon naming the various strata than that it was based upon timing them according to number or calendrical years. That rock strata and the fossil record actually present periods in time was only recognized by scholars such as Robert Hooke, William Smith and Charles Lyell. Both became recognized as relative time scales that for scholars such as Darwin formed the foundation to speculate on the gradualness of evolution. Absolute dating of the geological time scale only finalized with the introduction of radiometric dating techniques, something that happened as late as the 1950s (Braterman 2013). These absolute dates were formulated by physical constants on the hypothesized decay of the (half-)life cycles of various chemical minerals found inside the rocks and fossils. The years of these halflives remain formulated in what are called Julian days.

The rise of the geological time scale, expressed in names (e.g. the Cambrian, Ordovician, Silurian, Devonian, etc.) rather than numbers, in many ways was something entirely new. But seriation techniques had been used for centuries to develop scala naturae that line up the elements, genera and species, and the supernatural beings based upon their level of perfection; and they were the preferred means whereby moral philosophers and historians hypothesized on the laws or principles of change, and ethnologists and linguists classified their data accordingly. These timeless chronologies and seriations would be taken for granted by the early evolutionary scholars, and they would be evolutionized by simply adding time.

Greatly inspired by Lyell's uniformitarianism, Darwin (1859) was one of the first to speculate upon the rate of evolutionary change. In his Origin, he did so by basing his views on calculations of generations of individuals, i.e. by 
adding time to pedigrees and non-evolutionary genealogical trees.

Originally, networks and trees demonstrated the structural order of nature (Gontier 2011), but with the introduction of evolutionary thinking, these became the basic data whereupon natural history students would build chronologies: timelines of evolution. For Darwin, generations of organisms and their gemulles (what we today call genes) become the universal constant whereby all evolutionary motion becomes measured, simply because one has to wait for one generation to bring forth another, which immediately brings forth a sense of gradualism. While reproduction forms a hallmark of his theory of descent with modification, in his examination thereof, he could have taken the life cycles of organisms into account and calculated the length of years one generation of organisms of a particular species takes to reproduce. But as such, there would be no uniformity in time. Bacteria reproduce in minutes, fruit flies reproduce after 6 days, rabbits after 4.5-8 months depending on the species, and humans only after years. If Darwin would have been interested in modelling these reproductive cycles, he would have run into the problem of time and uniformity of motion. Instead, he calculated the number of generations by using the decimal number system, thereby investigating how evolution occurs over generations $1,2,3$, until they reach thousands.

More specifically, Darwin's (1859: 116-118) hypothetical diagram (Fig. 5) depicts species A to L, set at an "unequal distance" because "these species are supposed to resemble each other in unequal degrees, as is so often the case in nature." Focusing on species A, he goes on to describe how the dotted lines represent its various offspring which he calculates by generations. One horizontal line represents 1.000 generations, "The intervals between the horizontal lines in the diagram, may represent each a thousand generations; but it would have been better if each had represented ten thousand generations." After 1.000 such generations, he hypothesized that many of the offspring would not have been preserved by nature (the ones that do not reach the horizontal line). But a1 and $\mathrm{m} 1$, for example, would have diverged sufficiently from one another to have formed new varieties. After another 1.000 generations, a1 brings forth another variety, and $\mathrm{m} 1$ has brought forth 2. Darwin's hypothetical scenario continued until generation 10,000, and then in what he calls a "condensed and simplified form," until 14,000 generations.

So while he starts off by accepting the unequal preservation and selection of generations of offspring, as well as unequal divergence of varieties, he sets the time interval for significant divergence at a steady rate of 1000 generations. As such, through calculating not the reproductive cycles of individuals but the number of generations, he is able to homogenize the process of evolution for all different species, and he homogenizes the estimated time for significant divergence to take place.

Besides adding time, this also involves a switch from pedigree to tree-thinking (Gontier 2011), and that is exactly what Haeckel did when he introduced the first real evolutionary trees of life and mapped them unto the geological scale.

Similarly, the unilineal chronological seriations of the early natural history scholars would become evolutionized by the early social Darwinists, who took the hypothesized developmental stages for evolved ones, and over the years, they would try and add time. As such, the hypothesized historical chronology of European settlers, going from nomads to hunter gatherers to farmers to industrialized men thereby became the "natural history" against which all progress or regress of other ethnicities became measured (Gontier 2009). In sum, the widely used notions of development, regress and progress that founded many of the early historical seriation attempts, would simply be constituted for evolution, and the hypothesized chronologies would be converted into timelines.

A similar series of events can be detected in the study of development. The study of development went through a phase of preformationism, where following Aristotle, the life cycle of individual development (coming and becoming) was considered to be fixed and predestined, from sperm and/or egg to organism to death. The fixity of species and the predestined script of development thereby provided an idea of Greek uniformity of motion as well as repetition, one that for the Judeo-Christians demonstrated God's omnipotence. As such, it was more interesting for these early scholars to understand the linear sequence of development (by, for example, as Schedel did, distinguishing between the Ages of life) and thus to establish a chronological seriation of events, than that they focused on the actual timing of development within a number line.

With the introduction of Darwinian evolutionary ideas and especially mutation theories, scholars came to realize that the circle or cycle of development can be broken and the direction of evolution can be altered, and such first and foremost brings forth a quest for continuity and uniformity, which evolutionary scholars found in the cyclic regeneration of organisms that pass on their gemulles or genes, from one generation to the next.

Haeckel (1866), more inspired by the "positivistic" movements, instead imposed a Cartesian linearity onto development. Haeckel's biogenetic law first and foremost states that ontogenesis (development, the original subject of natural history) recapitulates phylogenesis (evolution), and he saw his law active in both the biological and sociocultural domain. New traits, for Haeckel, either become added by terminal addition, or old traits resurface through atavism. 


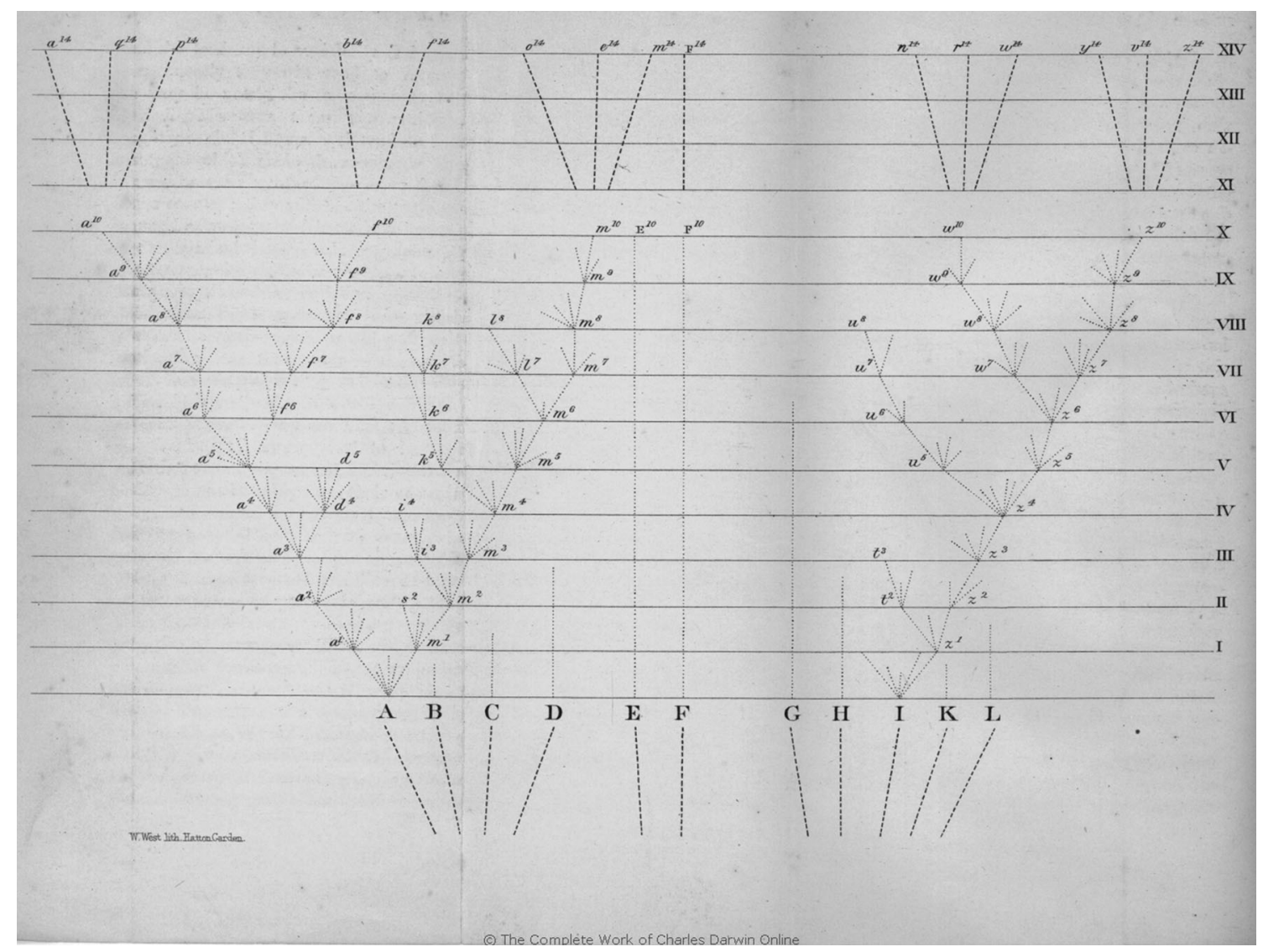

Fig. 5 Darwin's (1859: 116) hypothetical diagram on how species diverge. Obtained from http://darwin-online.org.uk/converted/published/ 1859_Origin_F373/1859_Origin_F373_fig02.jpg

In this regard, it is interesting that his idea was fiercely countered by Thompson (1917), for example, who attempted to understand the development of form, in a true Platonic sense and thus by going back to the ancients, by means of mathematics and geometry, a tradition that is today continued from within both physics and mathematics where scholars focus on the geometrical form of physiological structures, much more than on their evolution (e.g. Mandelbrot 1982; Stewart 2001).

Equally, early embryologists and epigeneticists such as von Bear, countered the law-like status that became attributed to natural selection theory by investigating the natural history of the number of cell generations (recurring cycles) it takes to develop an individual, and how perturbations in those recurring cycles bring forth evolution: change over time (Gould 1977; Schwartz 1999). This tradition today is continued by evo-devo schools, where the recurring interactions between genes and proteins are used to explain pattern formation or the evolution of a bauplan, i.e. the structure of developmental form. Though Gould only linked Eliade's work to his research on the geological time scale, where he distinguished between time's arrow and time's cycle, this distinction also enables one to understand his work on evo-devo.

There are more Cartesian and Newtonian moves to be found in Darwin's work that counter research on life cycles. In so far as Darwin endorsed a Lamarckian theory with regard to his ideas on gemulles and how they propagate, he investigated how external force, i.e. the environmental alteration of gemulles during an individual's life time and the selection by the outer environment of the organism, impacts the course of evolution. With the introduction of the Weismann barrier, an organism merely proposes and the environment disposes of the maladaptive, and no "inner wanting" of the individual can change that. Such ideas have since been countered by scholars such as Lewontin who introduced the idea of niche construction, and by scholars such as Williams and Dawkins that demonstrated how selection can be internalized, because selection not merely works at the organism-environment interface.

The work on punctuated equilibria that Gould developed in collaboration with Niles Eldredge (Eldredge and Gould 1972), can be understood as an attempt to counter both 
uniformitarianism and the Cartesian causal teleology it implies, by restoring natural history to a study of patterns and building a chronology thereof, that instead of finding laws, focusses on finding the rhythms or periodicities of speciation and extinction events. Eldredge (1995, 1999) would in this regard describe himself and scholars such as Vrba and Gould as "naturalists", while he characterized scholars such as Dawkins and Williams as "universal Darwinists". The former set out to find evolutionary patterns, while Eldredge attributes a form of "physics envy" to the latter for trying to turn natural selection into a physical law (for a discussion see Gontier 2015).

As inspired by empiricism as he was, Darwin also assumed a constant struggle for existence, an idea that has since been refuted by symbiologists who argue that the "law of competition" must be supplemented by "laws of cooperation" and "mutual aid" (for a discussion see Sapp 1994a, b; Gontier 2016), something that can only be studied by examining the life cycles of individuals.

In sum, the transformation of natural history research to evolutionary biological research in many ways can be characterized as a change in how the scholars involved conceptualize and measure time. Seriation or chronology which was above all an act of finding the patterns of nature, has become numerical, and with this change, scholars have attempted to transform historical patterns of nature into laws that can be calculated by number. Ever since Darwin and Haeckel, most evolutionary data has become depicted in Cartesian two-dimensional systems, where one axis represent time and the other represents how traits/organisms/species (matter) evolve (in space). In current trees of life that track back life to its very origins, time is often no longer expressed by the estimated number of generations as Darwin would have had it, but in calendrical years. And given the millions of years over which we now know evolution has taken place, we hardly have any affinity with the "years" that follow a number. We do not, for example, think about the 365/6 days that mark every single year that makes up the estimated 2 billion years of eukaryotic evolution, we simply focus on the number $(2.000 .000 .000)$ to build our sense of time.

\section{Modern Physics and Evolutionary Biology: The Problem of Time and Non-linear Dynamics}

Here we first analyze how linear Cartesian mechanics influenced Neo-Darwinian evolutionary biology; secondly, we investigate how modern physics understands matter, space and time as relative and how their theories bring forth a statistical causality that is founded upon the study of non-linear dynamics and probability equations. Thirdly, we return to evolutionary biology and investigate how evo- devo, reticulate evolution, and macroevolutionary schools of thought also focus on non-linear processes that underlie the change biological individuals undergo over time. Fourthly, we analyze how scholars that currently work from within an "extended" synthesis investigate different phenomena at different levels of the evolutionary hierarchy to "time" evolution, ranging from molecular clocks at the micro-level, to interactions between genes, organisms and species at a meso-level, and interactions between the living and abiotic environment at the macro-level.

1. Descartes reduced space to matter in a material plenum where ether was considered a kind of matter, and he defined time as an idea. The object of physical study for him was to find out how matter moves, which he defined as duration. We can quantify duration or the motion of matter by following its trajectory: we can deduce B (the effect or endpoint of motion) from A (its beginning or cause). Subsequently, causality becomes defined as a linear sequence going from A to B. Understanding cause and effect relationships as linear enables us to argue the logic that cause has antecedence while effect has contiguity in time; i.e. cause precedes effect. Such linear notion of causality in turn enables a teleological view, because we assume that we can predict the future or infer the past by (back)tracking the trajectory taken by the matter in motion. It also facilitates uniformitarian views, whereby we explain the matters of fact in a current time by pointing out events in an earlier period, and in classical physics, it is assumed that the conditions that cause A to result in B are invariant.

Any identification of causes and their effects requires us to link a minimum of two events distinct in time and space to one another. This linkage is done by formulating a set of conditions or rules. Scholars have often defined these conditions or rules that causally link separate events in terms of immutable and invariable "laws" and "forces" (e. g. Newton's law of gravitational force) or "mechanisms", notions that stem from a time when scholars thought the world was fixed and at best linearly progressive (where time follows a straight line). These ideas consolidate the uniformitarian views.

Natural selection, for example, following Darwin (1859), is a mechanism that operates according to the following set of rules or conditions. In any one generation, biological organisms portray differential variation, inheritance, and differential fitness and these "Darwinian principles" (as they are often called, Lewontin 1970), are conditional for "descent with modification" to occur in later generations of biological organisms. In other words, differential variation, inheritance and differential fitness of organisms older in time, are events linked to the modification of organisms later in time, and natural selection becomes a hypothesis for why there exist species, why there is common descent amongst them, and why there is 
descent with modification amongst them over time. It furthermore predicts that differential variation, inheritance and fitness will occur in the future.

2. As we saw, from Galileo onward, the physical sciences have reduced time to a mere quantum in order to measure motion. The before, during and after of an object in motion is measured by number, and these moments coincide with absolute time. The idea that absolute time is uniform is by and large determined by the use of a linear mathematical number system. That mathematics is uniform and linear is in turn determined by the causal teleology as it was introduced and depicted by Descartes and especially Newton. It is, as Heidegger $(1915,2006)$ demonstrated, the fundamental way by which classical physics, thermodynamics, classical mechanics, optics, magnetism and electricity studies understand time, and it enables a unification of these diverse sciences. And this notion of time has for the majority of studies conducted in modern evolutionary biology been used to depict the evolution of life over time by means of trees and networks.

In the equations of motion $-x=x(t), y=y(t)$, and $z=z(t)$ - time is presupposed as an independent variable that changes consistently, i.e. flows uniformly from one point to another without any leaps. Time is like a simple linear series in which each point of time is differentiated by its current position as measured from its initial position. Since any given point in time differs from the preceding one only by being the succeeding one, it is possible to measure time and therefore motion. As soon as time is measured (and time has a meaningful function in physics only as measurable and measuring), we can determine a quantitative 'how much'. This declaration of 'how much' gathers the already elapsed points of time into a unit. We make a cut, as it were, in the timescale, thereby destroying the proper flow of time and letting time congeal. The flow freezes, becomes a segment; and only as a segment can it be measured. Time has become a homogenous ordering of points, a scale, a parameter. (Heidegger 2006: 66)

Heidegger went on to demonstrate that general and special relativity theory "... corroborates to the highest degree what we spelled out earlier about the character of the concept of time in natural science, namely, its homogenous, quantitatively determinable character. Nothing could more clearly express the mathematical character of the concept of time within physics than the fact that time is posited as the fourth dimension alongside three-dimensional space and, together with it, is treated in a nonEuclidian geometry, one with more than three dimensions." (Heidegger 2006: 67)
The idea that time is cyclic annihilates any sense of history, and both the idea that time is merely a fiction or a concept of the mind, or the idea that time is absolute, also annihilate any sense of time. Saying that something is or is not, is not that interesting, because we can prove neither statement to be true or false. It becomes much more interesting when we can prove that matter, space or time do not exist always and everywhere, and that is exactly what current physics has done.

Einstein was able to equate matter with energy by proving that both are the same, but he struggled in particular with the concept of space. As we know, ether is one of the most debated substances in classic Aristotelian and Newtonian physics because it defines either the formation of light or the medium whereby light can travel. As such, it defines how and at what speed light moves $(299,792,458 \mathrm{~m} / \mathrm{s}$ which enables distance to be expressed in light years) and this is taken as a physical constant, a reference for how (fast) all matter (including earthly and celestial bodies) moves. Einstein (1920: 3) also endorsed the existence of ether, and in a paper on the subject asked: "How does it come about that alongside of the idea of ponderable matter, which is derived by abstraction from everyday life, the physicists set the idea of the existence of another kind of matter, the ether?" He answered by saying that "The explanation is probably to be sought in those phenomena which have given rise to the theory of action at a distance, and in the properties of light which have led to the undulatory theory," the theory that states that light is transmitted as waves. Einstein defined matter as "condensations of electromagnetic field" which means that matter is energy in a solid or gaseous form, and space as "gravitational ether or gravitational field" which is defined as the impact one mass of matter has on another from a distance. Later, scholars would find the concept of ether obsolete and use instead the term gravitational field. With it, both the concept of ether and (absolute) space become obsolete.

Minkowski (1908) combined space and time into a single space-time continuum which facilitated Einstein's special relativity theory, but this space-time does not yet take the curvature of space-time into account. This only happens with general relativity theory, where space-time can curve based upon its mass. This allows for the possibility of time to go slower or faster depending upon its distance from mass (Einstein 1907), something that is proven by gravitational time dilation experiments (Pound and Rebka 1959), and more recently by the gravitational waves or ripples in space-time that reached our earth in September 2015 and that resulted from the collision of two black holes 1.3 billion years ago (Moreva et al. 2014; Abbott et al. 2016).

3. Such has a profound impact on how we define causality. For starters, time or spacetime is not uniform. 
The shape of space-time "bends" by its mass. If change is conditional upon "matter in motion", and if space-time is relative according to its mass, then instead of assuming invariant or eternal laws of nature, or straight-line trajectories, we need to take the surroundings into account. A does not necessarily lead to $\mathrm{B}$, it only does so when the rules or conditions that commit $\mathrm{A}$ to $\mathrm{B}$ do not change. In other words, there can be outside variables that cause for perturbations in an otherwise linear causal sequence of the matter that is in motion (think of the butterfly effect or catastrophe theory, Gould 1989). And the idea that given a $\mathrm{B}$ there must be an $\mathrm{A}$ is also mutable, because $\mathrm{B}$ might have come into existence through $\mathrm{C}$ or $\mathrm{D}$-think of homoplasy, canalization and genetic assimilation, or reticulate evolution. Homologous traits are similar amongst various species because they share common descent and thus common gene sets (Hallgrîmsson and Hall 2011), while homoplastic traits are similar due to similar or shared environmental pressures, processes dubbed parallel and convergent evolution (Conway Morris 1998). During canalization and genetic assimilation (Waddington 1942), an environmentally induced phenotype becomes stable over generations in time despite differential environmental and genetic conditions. And during processes of lateral gene transfer and symbiogenesis (Gontier 2016), genes, plasmids or entire biological organisms are acquired from outside the genealogical descent-line, causing for non-genealogical descent with modification.

In other words, to explain these events, we cannot merely refer to an organism's particular past, we need to take into account it's, what Husserl would call, "extended present", where during ontogeny, the organism encounters distinctly evolved entities that can influence its life path as well as that of its future generations, and these interactions induce non-linear change.

When looked at in a hierarchical fashion, the lower levels of a hierarchy are not merely causally responsible for the focal levels (e.g. genes that underlie a bauplan), the higher levels can also influence the focal level through processes such as downward causation (Campbell 1974), as described in processes such as the Baldwin effect (1896). And when looked at in a context of timing, what is being used as a chronometer are interactions between different types of matter, ranging from the micro-meso to macrolevel.

Of course any event of parallel or convergent evolution, canalization, lateral gene transfer or symbiogenesis has its own particular past, i.e. its own particular multi-causal event chain or sets of sequences that led for that something to come into existence, but these combine a series of events distinct in space-time together into a new present, in a nonlinear causal fashion, and that new present in turn influences the future differentially. In the best case scenario, we humans are able to track these events, but every trajectory appears to have its own peculiarities making it difficult to postulate absolute "laws" of nature.

If inheritance, for example, is defined by the vertical transmission of genes from parent to offspring, as NeoDarwinians prefer, then there was a period when there was no selection because there were no replicating entities available yet, and the biochemical evolution that precedes the origin of these replicators and the reaching of what is often called the "Darwinian threshold", occurred by means of "spontaneous generation" which today is defined by selforganizing autocatalytic biochemical networks that are constrained by Pauli exclusion principles on how atoms bond.

Symbiogenesis explains the origin of some of the eukaryotic organelles, but also symbiogenesis is not a constant force or law. Only some cyanobacteria evolved into chloroplasts, most continued their particular evolutionary path in natural history, independently. Symbiogenesis is a mechanism that occurs through hereditary symbiosis, and hereditary symbiosis occurs rather frequently. Newborn infants, for example, are colonized differentially by microbial biota depending upon whether they came into the world via the birth canal or via a C-section. Through the birth canal, newborn infants receive numerous bacteria from their mother, and if girls, and if they reproduce, and if they do so without a c-section, they will in turn pass on these microbial communities to their infants.

Lateral gene transfer also occurs rather frequently, but the process is "contingent" upon environmental availability of transferrable genes as well as the organismal or genomic competence to either stand receptive toward foreign gene acquisition (in the case of bacterial conjugation in E. coli for example, where an F Factor is required), or the organism's incapacity to fence off foreign genetic agents (in the case of transduction or viral infections for example). And these "contingencies" in turn can just as well be called "necessities" for lateral gene transfer to take place, depending upon the position one takes. At the time, other options were available, but to explain the phenomena in hindsight, they form a necessary part of the sequence that gave way to the acquisition.

In any moment in time, we are left with a set of probabilities of which some are more likely than others, what I called a statistical causality in Table 1. Antecedence of cause and contiguity of the effect do not always form a linear pair in time for the simple reason that the conditions that cause for the natural world to change, can themselves vary and thus change over time. Modern physics and mathematics is currently demonstrating us that reasoning on causality need not follow the rigid linearity that is presumed to go from A to B, causality can be multi-variate 
linear or non-linear (Nolte 2014). These probabilities are measured in terms of distance apart, i.e. the possibility of one or more event(s) in space and time (or space-time) to have a causal influence on other event(s) distinct in space and time. To measure these likelihoods, we make use of combinatorics (Berge 1958; Biggs 1974), i.e. we count the distance between matter (which itself functions as a measurement of time, but in so far as distances vary, times vary with it). We count observable entities (A, B) and investigate how they relate to one another in an arithmetic way $(\mathrm{A}+\mathrm{B}, \mathrm{A}-\mathrm{B}$, A.B, A:B), and from this we deduce probabilities of influence. It is more likely that a cup falls and shatters into a thousand pieces, than that those thousand pieces shattered all over re-assemble into a cup. The former can be explained by the law of gravity, the reassemblage would require more "energy", but there is no law for or against it.

Combinatorics underlies any theoretical or figurative type of modelling of the world (such as graph theories), and any form of combinatorics immediately associates with part-whole divisions, reductionism versus holism debates, hierarchy theories and the division of the sciences. All require an observer or divider, and as such, all becomes relative based upon the divider's particular frame of reference or epistemological framework wherefrom he defines his subject area. And this brings forth a pluralistic stance.

4. Evolution has often been defined as the change that living beings go through in natural history and thus "in" or "over" time, and any investigation into natural history is built upon the classic physical notion of time as "succession of matter" or "matter in motion". But what matter do evolutionary scholars use nowadays to examine this succession of matter and how does this influence our notions of time and causality?

Macro-evolutionary scholars often seek causality in earthly events, micro-evolutionary scholars seek causality in genes, and meso-level oriented scholars seek causality in ecological interactions.

Micro-evolutionary, population geneticists, for example, point towards genes as the cause of heredity, and they track genetic changes vertically over generations of populations. As such, they deduce "time" from the biological organisms themselves, or better, they follow the motion of genes, that become understood as the "true survivors", while organisms are mere "vehicles" or mediums that facilitate genetic change (Dawkins 1983). When Zuckerkandl and Pauling (1965) introduced their "molecular clock", they argued that semantides (RNA, DNA and polypeptides) are a chronometer to measure and time evolution. So instead of looking at the earth's layers to time events, they look at the changes in molecular sequences that took place in time. Nonetheless, the approach is limited because eventually protein or gene-based trees need to become calibrated with when the organisms that incorporate them first show up in geological time which is set against numerical time.

At a meso-level, embryologists, symbiologists, ecologists, epigeneticists and behavioral scientists examine particular life histories and how, during ontogeny (itself the succession of forms that one organism goes through from birth to death), or stated otherwise, how during an extended present, organisms constantly acquire new forms, functions and behaviors, "information" from outside the germline that can potentially alter the organism's life course/cycle and perhaps have causal influence on its future descendants. As such, they investigate how non-linear events outside the genealogical descent line, disrupt an otherwise linear sequence of descent, by potentially adding new information that can causally influence future generations.

Studies on ecological interactions that organisms and species maintain amongst themselves and the abiotic environment, or research on ecological inheritance, epigenetic inheritance, hereditary symbiosis, or lateral gene transfer, therefore seek causation in the interactions between organisms, and these interactions in turn, provide yet another way to time change in natural history.

And on a macro-level, geologists and paleontologists have demonstrated that speciation and extinction events follow different periodicities, not all of which can be captured from within a framework of phyletic gradualism. Instead, as the theory of punctuated equilibria demonstrates, long periods of species stability or stasis are often intermitted by short punctuations of rapid change, and such change is not only due to gradual changes in gene frequencies, but often results from macro-events such as climate change, and they also take ecological interactions into account.

Scholars thus developed different means to study the matter that is in motion, and they do so on all scales of the biological hierarchy. These tendencies are somewhat consistent with modern physics where time is conflated with space into a single space-time continuum. Scholars today entertain differential spatio-temporal orientations (quantum observer positions) of matter. They use different entrypoints to study the matter that is in motion, ranging from the inorganic over the organic to the superorganic, and these different spatial orientations also demonstrates that the matter under study is diverse. There is thus no uniformity or homogeneity to take for granted, because though genes, organisms and species, in so far as they occupy space and time or have a spatio-temporal lifespan, are made up of matter, the matter under study is diverse.

It is therefore no wonder that these studies bring forth discussions not only on matter and space, but also on time through discussions on the pace and rate of evolution, as well as discussion on the hierarchy or order of the natural world and its associated notions of biological individuality. 
In so far as these subject areas are diverse, one can wonder if all define different notions of time. And in so far as all these different notions of time provide relative times, we need to find a way to bring these different periodicities together into a single theory of evolutionary time, because an absolute frame of reference is currently lacking. Alternatively, we give up on finding such an absolute time altogether. Networks that depict ecological relations, the biogeographic migration of organisms and the diffusion of languages or cultures, or the interactions that exist amongst the biotic and abiotic environment today often remain historically unrooted because unlike phylogenetic trees that focus on historical reconstructions, networks focus on depicting life in the extended present.

\section{But is Our Notion of Time Obsolete?}

It is clear by now that our notions of time pattern our research into the nature and natural history of the world. Question then is why this is the case. The above genealogy of Western cosmologies demonstrates that how we define time is to some extent culturally determined and as such it is also malleable and prone to change depending upon the culture framework or niche one works in or constructs, not only in Western but also in non-Western cultures (Sinha \& Gärdenfors 2014). But is time no more than a cultural construct? Here, we give three valid reasons that possibly allow us to continue endorsing the validity of time as a concept relevant for evolutionary biology. Firstly, our notion of time is also partly biologically determined, because it has been proven, as we will discuss, that our current conceptualization of time mimics our stream of consciousness. Secondly, in so far as time functions as a cognitive medium to conceptualize the world, and in so far as we have biologically and socio-culturally evolved this cognitive trait, we have evolved it as what can be considered an adaptive response to our environment. Thirdly, we are not alone in having evolved a "sense" of time, and no matter how one conceptualizes time or measures tempo, different biological phenomena follow different periodicities.

1. Contrary to Newton and Leibniz, Kant rejected the idea that there exists an absolute "unmovable" space (DePierris and Friedman 2013), and following Descartes and Hume, he understood time, defined as duration (or true time), as an a priori given, a presupposition or "pure form of the sensuous intuition" (Kant 1781 CPR, I, II, SS5), because we can neither think of the co-existence of separate entities or the totality of existence (simultaneity) nor of the succession of matter without time (while, according to Kant, we can think of time without phenomena, Janiak 2012).
In other words, time is the pattern or cognitive medium that helps us conceive "change" in natural history and change is defined as the motion or movement of matter in space. Time is not causally responsible for the change we see in the natural world, it is a medium that facilitates us to perceive the origin or beginning, succession or existence, and ending or death of a particular structural regularity of matter such as, for example, a living being. As such, time becomes a phenomenological item, something that we think, sense, or feel.

Hume (1739) furthermore pointed out that inferences on the past or predictions on the future are (mere) human expectations and that they are therefore better made sense of from within fields such as psychology (for a discussion, see Gontier 2015).

Following Hume and Kant, early phenomenologists (Husserl 1964; Russell 1913) and psychologists (James 1890, 1909; Mabbott 1955) started to investigate our notions of causality and time from within the cognitive sciences. Such research has shown that dividing events into a past, present and future mimics our stream of consciousness and the way we experience our existence, and a strong case can be made for arguing that we have imposed or incorporated such linearity into our linguistic and mathematical systems as well as into our epistemologies by which we define causality.

Because such causal linearity and teleology is deeply embedded in our cognitive, linguistic and mathematical systems, we are used to call it logical.

Nonetheless, such linear and uniform time- and causality-thinking is also determined culturally, because although ancient languages of course had tense (see Plato's citation where he mentions that only "is" is applicable to true being, but not "was" or "shall be"), we know the associated cosmologies endorsed a cyclic view of time and a cyclic notion of teleology, mostly because of their sexagesimal number system. As we saw, the switch from cyclic to linear cosmologies correlate with the switch from sexagesimal to decimal calculation systems that provided for a linearization of the early mathematics (Chrisomalis 2010; Macey 1989; Rudman 2007). The temporal division of decimal mathematics allows us to predict that 2 and 3 together will give 5 (and predictions always have a futuristic orientation), and that $5-3$ eventually brings us back to 2 (and inferences are always drawn about the past). This linear time-thinking became foundational for mechanical causality that, just because we assume that we can make predictions on the future and inferences from the past, remains teleological. It is important to note that the above number talk is not simply a word game, it is part of our linguistic systems where we use tense to link different events in time and space together into a linear sequence to make sense of the world. 
But while time is the cognitive medium through which we experience change at a phenomenological level, it's ontological existence is questioned with opinions ranging from the reality of time (Mangabeira Unger \& Smolin 2014) to its unreality (McTaggart 1908).

2. In so far as we do use concepts such as time and space to order our consciousness, languages, mathematics and our notions of causality, they must have evolved. The modern evolutionary sciences, and by following classic philosophical and psychological traditions, understand time as an evolved cognitive medium that enables us humans to organize our "flow of consciousness" and to navigate in the world (Atance \& O'Neill 2001; Ferretti 2014; Pöppel 1985; Sinha \& Gärdenfors 2014; Suddendorf and Corballis 1997; Varela 1999).

From within an evolutionary epistemological stance, we can argue that in so far as space and time are evolved cognitive traits that enable us to navigate in the world, they must have evolved in relation to something, and one can even say that having any sense of time and space is adaptive because not having any often leads to insanity (Corballis 2013).

3. What is more, we are not alone in our sense of time. Especially the field of chronobiology has been able to differentiate more and more "biological clocks" in association with microevolutionary phenomena such as geneswitching in molecular biology; meso-phenomena including heterochrony or the periodic changes of somatic and sexual developmental processes, bio-gerontology or the study of aging, and dormancy or the study of environmentally/seasonally induced periodicities of lower activity (with examples including diapause, hibernation/brumation, horticultural stratification, and circadian rhythms associated with diurnal and nocturnal lifestyles); speciation and extinction events of species, genera and clades on a macroscale.

So while the physical sciences question the existence of time and put any notion thereof on par with space, and while the emerging cosmologies provided by quantum mechanics are currently attempting to explain the universe in what can be characterized as a, for us humans, counterintuitive way, with so many species having evolved a sense of periodicity and time, time remains crucial for the evolutionary sciences, both as a topic for research and as a way to model our past.

\section{Summary}

In this article we have, firstly, provided a historical genealogy of western cosmological thought that transitioned from the ancient Greek cosmologies to JudeoChristian cosmology, to the rise of classical physics and early natural history schools, to modern physics and evolutionary biology.

Secondly, we have analyzed these cosmologies by their cosmographies that transitioned from Far and Middle Eastern wheels of time and ancient Greek chains of being to Judeo-Christian scala naturae and scientific tree diagrams to current network diagrams. Network diagrams indeed already originate in the 19th century where natural history scholars used them to examine the affinity between natural kinds and the ecological interactions they entertain as well as to depict their biogeography or diffusion in space, but in so far as these investigations developed outside the framework provided by the Modern Synthesis, these network typologies currently associate with schools that belong to an extended synthesis.

Thirdly, we have demonstrated that how cosmologies cartography and define matter, space and especially time correlate with how they differentially define causality. The ancient Greeks endorsed a cyclic notion of time and a cyclic notion of teleology. Judeo-Christian cosmology distinguished between eternity and created, historical time that they understood as both cosmogonic and eschatological, and they endorsed a chronological notion of teleology that was non-uniform because in their theistic worldviews, their deity could intervene in creation by divine will, not in the least by creating relative time, by presumably giving humans knowledge thereof via language and mathematics, and by having the power to end it. Classical physics distinguished absolute, mathematical time from relative time and endorsed linear and mechanical notions of causality while with the introduction of the notion of space-time, modern physics endorses statistical notions of causality that calculate probabilities and give uncertainties. These latter moves are somewhat mimicked by natural history scholars that first developed name-based historical/developmental chronologies to which they then tried to add time. With the rise of the geological time scale and Darwin's attempt to calculate the rate of evolutionary change, evolutionary biologists too have started to distinguish relative times from an absolute numerical time that is defined by number. Evolutionary biologists active in fields such as evo-devo and epigenetics, ecology, symbiology and lateral gene transfer, furthermore investigate how non-linear dynamics and non-genealogical interactions perturbate the life cycles of individuals thereby bringing forth statistical probabilities and uncertainties of how change occurs.

Fourthly, we have demonstrated that the introduction of different time notions correlates with advances we made in mathematics. Ancient Greek notions of time are derived from older, non-Western sexagesimal number systems that developed in Vedic India and the Levant, especially in relation to the establishment of zodiacal systems and attempts to predict the weather. Judeo-Christian cosmology 
transitioned from these ancient sexagesimal and circular cosmologies to a linear cosmology by adopting the Julian calendar as well as the decimal number system. Evidence is found in their almanacs that follow the older sexagesimal traditions, as well as in their semi-religious chronologies that they formulated in for them created numerical time, to explain how unique series of historical events in time and space correlate to one another, not by number, but by divine will. With the rise of classical physics, time becomes subordinated to the decimal number system that starts to function as a quantum to examine the succession of matter in motion that becomes depicted in the Cartesian two-dimensional coordinate system. And natural history research takes off by reformulating the older scala naturae and historical chronologies into evolutionary theories. In both the biological and the physical sciences, uniformity is found by quantifying change by uniform number lines.

Fifthly, we have examined how the recognition of the relativity of matter, space and time in modern physics as well as the development of non-linear mathematical tools to model the latter have on the one hand incited scholars active in the extended synthesis to model and quantify evolutionary change differentially, ranging from molecular clocks at a micro-level to interactions between different units and levels of the evolutionary hierarchy on a mesolevel to investigations into the periodicities that underlie speciation and extinction events on a macroscale. And on the other, it has made scholars question the very existence of time.

Sixthly, this has brought forth a fundamental gap between modern physics and evolutionary biology, because eventually, it remains the goal of evolutionary biologists to calibrate the different timescales (obtain from fossils, geological strata, molecular clocks or relative dating techniques) to an absolute numerical time. The reason why is clear, evolution is defined as the change organisms go through in or over time, and most evolutionary models continue to use time as an axis to map evolutionary change. The alternative can only be to model evolution by making use of unrooted trees or networks. But such questions the very premise of evolutionary biology that sets forth to explain the evolution of species over time.

Seventhly, the above points demonstrate that our notions of time pattern our research into the nature and natural history of the world. Question then is why this is the case. The above given genealogical analysis demonstrates that how we define time is to some extent culturally determined and as such it is also malleable and prone to change depending upon the culture framework one works in. But at least our current notion of time is also partly biologically determined, because it has been proven in phenomenological schools and modern-day psychology, that our current conceptualization of time mimics our stream of consciousness. And we can even think of circular time notions as a cognitive means whereby we try and make sense of distinct events in time and space.

Eighthly, three valid reasons are given for why we can continue to accept time as a valid notion in evolutionary biology. Firstly, time is not merely a cultural construct, it is also a cognitive notion that mimics our stream of consciousness. Secondly, in so far as time functions as a cognitive medium to conceptualize the world, and in so far as we have biologically and socio-culturally evolved this cognitive trait, it is an outcome of evolution. As such one can prove that time, at least for us humans, is real in so far as we can prove the evolution of time as a cognitive medium. Thirdly, we are not alone in having evolved a "sense" of time, and no matter how one conceptualizes time or measures tempo, different biological phenomena follow different periodicities. For these reasons, we can argue that time, at least for the biological sciences, remains a valid concept.

Acknowledgments This work was funded by the Portuguese Fund for Science and Technology (Grant ID SFRH/BPD/89195/2012 and Project ID UID/FIL/00678/2013). Cordial thanks also go out to Michael Bradie, Francesco Ferretti, Bendedikt Hallgrímsson, Henrique Leitão, Kate Maschmeyer, Eric Schliesser and Chris Sinha.

\section{Compliance with Ethical Standards}

Conflict of interest None.

\section{References}

Abbott, B. P., LIGO Scientific Collaboration and Virgo Collaboration, et al. (2016). Observation of gravitational waves from a binary black hole merger. Physical Review Letters, 116, 061102.

Aristotle. (2008/350 BCE). Physics (R. P. Hardie \& R. K. Gaye, Trans.). MIT Classics. http://classics.mit.edu/Aristotle/physics.2. ii.html.

Aristotle. (2012/350 BCE). Metaphysics (R. B. Jones, Ed., W. D. Ross, Trans.). MIT Classics. http://classics.mit.edu/Aristotle/ metaphysics.5.v.html.

Ashmand, J. M. (Ed.). (1822). Ptolemy's Tetrabiblos. London: Davis and Dickson.

Atance, C., \& O'Neill, D. (2001). Episodic future thinking. Trends in Cognitive Science, 5, 533-539.

Baldwin, J. M. (1896). A new factor in evolution. American Naturalist, 30(354), 441-451.

Barnes, J. (1984). The complete works of Aristotle. Princeton: Princeton University Press.

Berge, C. (1958). Théorie des graphes et ses applications. Collection Universitaire de Mathématiques, II. Paris: Dunod.

Biggs, N. L. (1974). Algebraic graph theory. Cambridge, MA: Cambridge University Press.

Braterman, P. S. (2013). Stumbling toward an understanding of geologic timescales. Scientific American, 17. http://dafix.uark. edu/danielk/Darwin/AgeEarthReadings.pdf.

Campbell, D. T. (1974). Evolutionary epistemology. In P. A. Schlipp (Ed.), The philosophy of Karl Popper (Vol. I, pp. 413-459). New York, NY: LaSalle. 
Cavalli-Sforza, L. L. (2000). Genes, peoples, and languages. New York, NY: North Point Press.

Champollion-Figeac, J.-J. (1832). Égypte ancienne. Paris: Typographie de Firmin Didot Frères.

Chrisomalis, S. (2010). Numerical notation: A comparative history. Cambridge, MA: Cambridge University Press.

Conway Morris, S. (1998). The crucible of creation: The Burgess Shale and the rise of animals. Oxford: Oxford University Press.

Copernicus, N. (1939). On the revolutions of the heavenly spheres, translated by C. G. Wallis. Annapolis: St John's College Bookstore.

Corballis, M. C. (2013). Mental time travel: A case for evolutionary continuity. Trends in Cognitive Science, 17(1), 5-6.

Darwin, C. (1859). On the origin of species. London: John Murrey.

Dawkins, R. (1983). Universal Darwinism. In D. L. Hull \& M. Ruse (Eds.), The philosophy of biology (pp. 15-35). New York, NY: Oxford University Press.

De Libera, A. (1995). La philosophie médiévale. Paris: Presses Universitaires de France.

Decaen, C. A. (2004). Aristotle's ether and contemporary science. The Thomist, 68, 375-429.

DePierris, G., \& Friedman, M. (2013). Kant and Hume on causality. In Zalta, E. N. (Ed.), The stanford encyclopedia of philosophy (Winter 2013 Edition). http://plato.stanford.edu/archives/ win2013/entries/kant-hume-causality/.

Derrida, J. J. (1981). Dissemination, translated by B. Johnson. Chicago, IL: University of Chicago Press.

Descartes, R. (1998). Discourse on method and Meditations on first philosophy, translated by D.A. Cress (4th ed.). Indianapolis: Hackett Publishing Company.

Dreyer, J. L. (1953). A history of astronomy from Thales to Kepler. New York, NY: Dover.

Einstein, A. (1907). Über das Relativitätsprinzip und die aus demselben gezogenen Folgerungen. Jahrbuch der Radioaktivität und Elektronik, 4, 411-462.

Einstein, A. (1920). Ether and the theory of relativity. In Barker, G. A., Perret, J. W. (Eds.), (1922). Sidelights on relativity (pp. $3-$ 24). London: Methuen.

Eldredge, N. (1995). Reinventing Darwin: The great debate at the high table of evolutionary theory. New York: Wiley.

Eldredge, N. (1999). The pattern of evolution. New York, NY: W. H. Freeman and Co.

Eldredge, N., \& Gould, S. J. (1972). Punctuated equilibria: An alternative to phyletic gradualism. In T. J. M. Schopf (Ed.), Models in paleobiology (pp. 82-115). New York, NY: Freeman, Cooper and Co.

Eliade, M. (1954). Cosmos and history: The myth of the eternal return, translated by W. R. Trask. New York: Harper Torchbooks.

Ferretti, F. (2014). Travelling in time and space and the origins of language. Humana Mente, 27, 243-268.

Galilei, G. (1974). Two new sciences, translated and annotated by D. Stillman. Wisconsin, MA: University of Wisconsin Press.

Gheverghese, J. (2011). The crest of the peacock: Non-European roots of mathematics (3rd ed.). Princeton, NJ: Princeton University Press.

Gingerich, O. (1984). Astronomical scrapbook: The origin of the zodiac. Sky Telescope, 67, 218-220.

Gontier, N. (2009). The origin of the social approach in language and cognitive research exemplified by studies into the origin of language. In H. Pishwa (Ed.), Language and social cognition: Expressions of the social mind (pp. 25-46). Berlin: Mouton de Gruyter.

Gontier, N. (2011). Depicting the tree of life: The philosophical and historical roots of evolutionary tree diagrams. Evolution, Education and Outreach, 4(3), 515-538.
Gontier, N. (2015). Uniting micro- with macroevolution into an extended synthesis: Reintegrating life's natural history into evolution studies. In E. Serrelli \& N. Gontier (Eds.), Macroevolution: Explanation, interpretation and evidence (pp. 227-278). Dordrecht: Springer.

Gontier, N. (2016). Symbiosis, history of. In R. M. Kliman (Ed.), Encyclopedia of evolutionary biology (Vol. 4, pp. 272-281). Oxford: Academic Press.

Gould, S. J. (1977). Ontogeny and phylogeny. Cambridge, MA: Belknap, Harvard Univrsity Press.

Gould, S. J. (1987). Time's arrow, time's cycle. Cambridge, MA: Harvard University Press.

Gould, S. J. (1989). Wonderful life. London: Penguin.

Griffith, R. T. (1896). The Rig Veda, Complete. Benares.

Haeckel, E. (1866). Generelle morphologie der organismen: allgemeine grundzüge der organischen formen-wissenschaft, mechanisch begründet durch die von $C$. Darwin reformirte decendenz-theorie. Berlin: Georg Reimer.

Hallgrîmsson, B., \& Hall, B. K. (2011). Epigenetics: The context of development. In B. Hallgrîmsson \& B. K. Hall (Eds.), Epigenetics: Linking genotype and phenotype in development and evolution (pp. 424-438). Berkeley, CA.: University of California Press.

Heidegger, M. (1915). Der Zeitbegriff in der Geschichtswissenschaft. Zeitschrift für Philosophie und Philosophische Kritik, 161, 173188.

Heidegger, M. (1915/2006). The concept of time in the science of history. In Kisiel, T., \& Sheenan, T. (2006). Becoming Heidegger: On the trail of his early occasional writings, 1910-1927 (pp. 60-73). Evaston, IL: Northwestern University Press.

Hume, D. (1739). A treatise on human nature. In L. A. Selby-Bigge (Ed.), Oxford: Oxford University Press.

Husserl, E. (1964). The phenomenology of internal time-consciousness, translated by J. Churchill. The Hague: Martinus Nijhoff.

James, W. (1890). The principles of sychology. New York: Dover.

James, W. (1909). A pluralistic universe. London: Longmans.

Janiak, A., Kant's views on space and time, In Zalta, E. N. (Ed.), The Stanford encyclopedia of philosophy (Winter 2012 Edition). http://plato.stanford.edu/archives/win2012/entries/kantspacetime.

Kant, I. (1998/1781). Critique of pure reason, translated by Paul Guyer and Allen Wood. Cambridge: Cambridge University Press.

Kaplan, R. (2000). The nothing that is: A natural history of zero. Oxford: Oxford University Press.

King, L. W. (1902). Enuma Elish: The epic of creation, from the seven tablets of creation. London: Kings College.

Kurzweil, F. (1956). Das Pentagondodekaeder des Museums Carnuntinum und Seine Zwechbestimmung (pp. 23-29). Carnuntus Jahrbuch.

Kuzmina, E. E. (2007). The origin of the Indo-Iranians. In J. P. Mallory (Ed.), Brill: Leiden Indo-European Etymological Dictionary Series.

Lewontin, R. (1970). The units of selection. Annual Review of Ecological Systems, 1, 1-18.

Livingstone, A. (2012). Hemerology and menology. The Encyclopedia of Ancient History. doi:10.1002/9781444338386. wbeah 21163.

Lochtefeld, J. (2002/1957). The illustrated encyclopedia of Hinduism (Vol. 1, pp. 744-745). New York: Rosen Pub Group.

Lyell, C. (1830, 1832, 1833). Principles of geology, being an attempt to explain the former changes of the Earth's surface, by reference to causes now in operation (Vol. 1-3). London: John Murray.

Mabbott, J. D. (1955). The specious present. Mind A Quarterly Review of Psychology and Philosophy, 64(255), 376-383. 
Macey, S. (1989). The dynamics of progress: Time, method, and measure. Athens, GA: University of Georgia.

Mandelbrot, B. (1982). The fractal geometry of nature. New York: W. H. Freeman \& Co.

Mangabeira Unger, R., \& Smolin, L. (2014). Singular universe and the reality of time. Cambridge: Cambridge University Press.

Martineau, H. (1865). The positive philosophy of Auguste Comte (1853), 2 volumes. London: Chapman.

McTaggart, J. E. (1908). The unreality of time. Mind A Quarterly Review of Psychology and Philosophy, 17, 457-484.

Mereaux-Tanguy, P. (1975). Le dodécaèdre: mesureur d'angle. Kadeth, 13, 28-31.

Minkowski, H. (1908). Space and time. In J. C. C. Smart (Ed.), Problems in space and time (pp. 297-312). London: Macmillan.

Moreva, A., Brida, G., Gramegna, M., et al. (2014). Time from quantum entanglement: An experimental illustration. Physical Reviews A, 89, 052122. doi:10.1103/PhysRevA.89.052122.

Neugebauer, O., Sachs, A. J., \& Götze, A. (1945). Mathematical cuneiform texts. Boston, MA: American Oriental Society and the American Schools of Oriental Research.

Newton, I. (1728). The chronology of Ancient Kingdoms Amended: To Which is Prefix'd, A Short Chronicle From the First Memory of Things in Europe, to the Conquest of Persia by Alexander the Great. London: J. Tonson, J. Osborn and T. Longman.

Nolte, D. D. (2014). Introduction to modern dynamics: Chaos, networks, space and time. Oxford: Oxford University Press.

Nouwen, R. (1993). De Romeinse pentagon-dodecaëder: mythe en enigma (p. 45). Hasselt: Publicaties van het Gallo-Romeins Museum te Tongeren, Limburg.

Nouwen, R. (1994). Les dodécaèdres gallo-romains ajourés et bouletés. Histoire et problèmes. BIAL, 106, 85-108.

Ôhashi, Y. (1993). Development of astronomical observations in Vedic and post-Vedic India. Indian Journal of History of Science, 28(3), 185-251.

Ôhashi, Y. (2014). Astronomy of the Vedic age. In C. Ruggles (Ed.), Handbook of archaeoastronomy and ethnoastronomy (pp. 19491958). New York: Springer.

Pinch, G. (2004). Egyptian mythology: A guide to the gods, goddesses, and traditions of ancient Egypt. Oxford: Oxford University Press.

Pingree, D. (1973). The Mesopotamian origin of early Indian mathematical astronomy. Journal for the History of Astronomy, 4, 1-12.

Pingree, D. (1981). Jyotihśāstra: Astral and mathematical literature. Wiesbaden: Otto Harrassowitz.

Plato. (1960). Plato: Timaeus, Critias, Cleitophon, Menexenus, Epistles, edited and translated by R. G. Bury. Cambridge, MA: Loeb Classical Library.

Plofker, K. (2009). Mathematics in India. Princeton, NY: Princeton University Press.

Pöppel, E. (1985). Mindworks: Time and conscious experience. New York: Harcourt Brace Jovanovich.

Popper, K. (1957). The poverty of historicism. London: Routledge.

Porceddu, S., Jetsu, L., Lyytinen, J., Kajatkari, P., Lehtinen, J., Markkanen, T., et al. (2008). Evidence of periodicity in ancient Egyptian calendars of lucky and unlucky days. Cambridge Archaeological Journal, 18(3), 327-339.

Pound, R. V., \& Rebka, G. A., Jr. (1959). Gravitational red-shift in nuclear resonance. Physical Review Letters, 3(9), 439-441.

Rogers, J. H. (1998). Origins of the ancient constellations: I. The Mesopotamian traditions. Journal of the British Astronomical Association, 108, 9-28.
Rosen, E. (1971). Three Copernican treatises: The Commentariolus of Copernicus; The letter against Werner; The Narratio Prima of Rheticus, translated with introduction and notes by Edward Rosen (3rd edn., revised with a biography of Copernicus and Copernicus bibliographies 1939-1958 and 1959-1970). New York, NY: Octagon Books.

Rudman, P. S. (2007). How mathematics happened: The first 50.000 years. Amherst, NY: Prometheus Books.

Russell, B. (1913/1984), On the experience of time. In Ramsden Aemes, E. (Ed.). The collected papers of Bertrand Russell (Vol. 7). London: Allen and Unwin.

Samuel, A. E. (1972). Greek and Roman chronology: Calendars and years in classical antiquity. München: C.H. Beck Verlag.

Sapp, J. (1994a). Evolution by association. New York: Oxford University Press.

Sapp, J. (1994b). Evolution by association: A history of symbiosis. New York: Oxford University Press.

Scaliger, J. J. (1583). Opus novum de emendatione temporum: In octo libros. CVM Privilegio. https://books.google.pt/books?id= R2xEAAAAcAAJ\&hl=nl\&pg $=$ PP13\#v=onepage \&q \&f=false.

Schaefer, B. E. (2002). The latitude and epoch for the formation of the southern Greek constellations. Journal for the History of Astronomy, 33, 313-350.

Schaefer, B. E. (2006). The origin of the Greek constellations. Scientific American, 295(5), 96-101.

Schedel, H. (1493). The Nuremberg chronicle: A facsimile of Hartmann Schedel's Buch der Chroniken, translated by Georg Alt. Brussel: Anton Koberger. https://books.google.pt/books?id= IeUOAQAAMAAJ\&hl=nl\&pg=PR9\#v=onepage $\& \mathrm{q} \& \mathrm{f}=$ false.

Schliesser, E. (2013). Newton's philosophy of time. In H. Dyke \& A. Bardon (Eds.), A companion to the philosophy of time (pp. 87101). New York: Wiley.

Schwartz, J. (1999). Sudden origins. New York: Wiley.

Sellars, J. (2007). The death of gods in ancient Egypt: A study of the threshold of myth and the frame of time, revised edition. Lulu.com.

Sinha, C., \& Gärdenfors, P. (2014). Time, space, and events in language and cognition: A comparative view. Annals of the New York Academy of Sciences, 1326(1), 72-81.

Stewart, I. (2001). What shape is a snowflake? Magical numbers in nature. New York: W. H Freedman.

Suddendorf, T., \& Corballis, M. C. (1997). Mental time travel and the evolution of the human mind. Genetic, Social, and General Psychology Monographs, 123, 133-167.

The Bible. (1997). Authorized King James version with Apocrypha. Oxford: Oxford University Press.

Thompson, D. W. (1917). On growth and form. Cambridge: Cambridge University Press.

Vahnia, M. N., \& Yadav, N. (2011). The origin and growth of astronomy as viewed from an Indian context. In W. Orchiston, et al. (Eds.), Highlighting the history of astronomy in the AsiaPacific region: Astrophysics and space science proceedings (pp. 61-84). New York: Springer.

Varela, F. (1999). Present-time consciousness. Journal of Consciousness Studies, 6(2-3), 111-140.

Waddington, C. H. (1942). Canalization of development and the inheritance of acquired characters. Nature, 150(3811), 563-565.

Zuckerkandl, E., \& Pauling, L. (1965). Molecules as documents of evolutionary history. Journal of Theoretical Biology, 8, 357-366. 